Supporting Information for

\title{
A New Approach to the Neoglycopeptides: Synthesis of Urea- and Carbamate-tethered $N$-Acetyl-D-glucosamine Amino Acid Conjugates
}

\author{
Yoshiyasu Ichikawa, * Fumiyo Ohara. Hiyoshizo Kotsuki, Keiji Nakano \\ Faculty of Science, Kochi University, Akebono-cho, Kochi 780-8520, Japan. \\ Tel: +81-88-844-8292, FAX: +81-88-844-8359 \\ E-mail: ichikawa@cc.kochi-u.ac.jp
}

I. Experimental Procedures and Characterization Data for 3, 5, 2, 7a-f, 13, 14, 16 and compounds in reference $(16)$ and $(19) \quad \ldots \ldots \ldots \ldots \ldots \ldots \ldots \ldots \ldots$

II. ${ }^{1} \mathrm{H}$ and ${ }^{13} \mathrm{C}$ NMR Spectra for All Relevant Compounds $\quad \ldots \ldots \ldots \ldots \ldots \ldots \ldots$ 


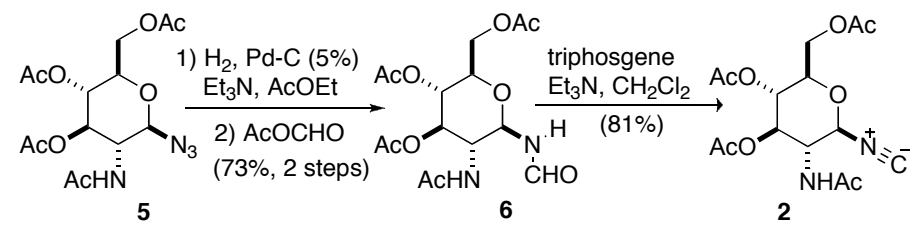

Synthesis of isonitrile 2 from azide 5. A solution of $N$-acetylglucosyl azide 5 $(2.00 \mathrm{~g}, 5.4 \mathrm{mmol})$, triethylamine $(2.20 \mathrm{ml}, 16.2 \mathrm{mmol})$ and palladium on carbon $(5 \%$, $200 \mathrm{mg}$ ) in AcOEt $(44.0 \mathrm{ml})$ was stirred vigorously under hydrogen atmosphere for 30 min, and the resultant reaction mixture was treated with acetic formic anhydride $(2.22$ $\mathrm{ml}, 27.0 \mathrm{mmol}$ ). After being stirred at room temperature for $30 \mathrm{~min}$, the reaction mixture was filtered on Super Cell, and then concentrated. Purification by silica gel chromatography (3:1 AcOEt/hexane) afforded formamide $6(1.50 \mathrm{~g}, 73 \%)$ as a white solid: $\mathrm{mp} 192-193{ }^{\circ} \mathrm{C} ;[\alpha]_{\mathrm{D}}{ }^{21}=+9.4\left(c 0.50, \mathrm{CHCl}_{3}\right)$; IR $(\mathrm{KBr}) v_{\max } 3071,1751 \mathrm{~cm}^{-1} ;{ }^{1} \mathrm{H}$ NMR (400 MHz, $\left.\mathrm{CDCl}_{3}\right) \delta 1.97(3 \mathrm{H}, \mathrm{s}), 2.06(3 \mathrm{H}, \mathrm{s}), 2.08(3 \mathrm{H}, \mathrm{s}), 210(3 \mathrm{H}, \mathrm{s}), 3.78$ (1H, ddd, $J=10.0,5.0,2.0), 4.10(1 \mathrm{H}, \mathrm{dd}, J=12.5,2.0), 4.17(1 \mathrm{H}, \mathrm{dt}, J=10.0,9.0)$, $4.30(1 \mathrm{H}, \mathrm{dd}, J=12.5,5.0), 5.06(1 \mathrm{H}, \mathrm{t}, J=9.0), 5.13(1 \mathrm{H}, \mathrm{t}, J=9.0), 5.16(1 \mathrm{H}, \mathrm{t}, J=$ 9.0), $6.34(1 \mathrm{H}, \mathrm{d}, J=8.5), 7.11(1 \mathrm{H}, \mathrm{d}, J=8.5), 8.21(1 \mathrm{H}, \mathrm{s}) ;{ }^{13} \mathrm{C}$ NMR $(100 \mathrm{MHz}$, $\left.\mathrm{CDCl}_{3}\right) \delta 20.6,20.7,23.1,531,61.7,67.8,72.8,73.6,78.6,161.6,169.3,170.7,171.8$, 172.0. Anal. Calcd for $\mathrm{C}_{15} \mathrm{H}_{22} \mathrm{~N}_{2} \mathrm{O}_{9}$ : C, 48.13; H, 5.92; N, 7.48. Found: C, 48.38; H, $6.07 ; \mathrm{N}, 7.38$.

To a solution of formamide $6(100 \mathrm{mg}, 0.27 \mathrm{mmol})$ and triethylamine $(0.30 \mathrm{ml}, 2.16$ mmol) dissolved in $\mathrm{CH}_{2} \mathrm{Cl}_{2}$ cooled to $0{ }^{\circ} \mathrm{C}$ was added triphosgene (80 $\mathrm{mg} 0.27 \mathrm{mmol}$ ) portionwise. After stirring at $0{ }^{\circ} \mathrm{C}$ for $5 \mathrm{~min}$, the cooling bath was removed. The reaction mixture was stirred at room temperature for $2 \mathrm{~h}$, and then poured into aqueous $\mathrm{NaHCO}_{3}$. The aqueous layer was extracted with $\mathrm{CH}_{2} \mathrm{Cl}_{2}$, and combined organic extracts were washed with brine, dried $\left(\mathrm{Na}_{2} \mathrm{SO}_{4}\right)$, and concentrated. The resultant residue was purified by silica gel chromatography (3:1 AcOEt/hexane) to afford isonitrile $2(78 \mathrm{mg}, 81 \%)$ as a white solid: $\mathrm{mp} 151-152{ }^{\circ} \mathrm{C} ;[\alpha]_{\mathrm{D}}{ }^{21}=+28.4(\mathrm{c} 1.00$, $\mathrm{CHCl}_{3}$ ); IR (KBr) $v_{\max } 2141,1752 \mathrm{~cm}^{-1} ;{ }^{1} \mathrm{H} \mathrm{NMR}\left(400 \mathrm{MHz}, \mathrm{CDCl}_{3}\right) \delta 2.01(3 \mathrm{H}, \mathrm{s})$, $2.03(3 \mathrm{H}, \mathrm{s}), 2.05(3 \mathrm{H}, \mathrm{s}), 2.11(3 \mathrm{H}, \mathrm{s}), 3.78(1 \mathrm{H}, \mathrm{ddd}, J=10.0,5.0,2.0), 3.93(1 \mathrm{H}, \mathrm{q}, J$ 
=9.0), $4.15(1 \mathrm{H}, \mathrm{dd}, J=12.5,2.0), 4.26(1 \mathrm{H}, \mathrm{dd}, J=12.5,5.0), 5.08(1 \mathrm{H}, \mathrm{dd}, J=10.0$, 9.5) $5.23(1 \mathrm{H}, \mathrm{d}, J=9.5) 5.41(1 \mathrm{H}, \mathrm{dd}, J=10.0,9.5) 6.02(1 \mathrm{H}, \mathrm{br}) ;{ }^{13} \mathrm{C} \mathrm{NMR}(100 \mathrm{MHz}$, $\left.\mathrm{CDCl}_{3}\right) \delta 20.5,20.6,23.1,55.2,61.6,67.9,71.0,74.2,79.5,162.8,169.2,170.4,170.6$, 171.2. Anal. Calcd for $\mathrm{C}_{15} \mathrm{H}_{20} \mathrm{~N}_{2} \mathrm{O}_{8}$ : C, 50.56; H, 5.66; N, 7.86. Found: C, 50.46; H, $5.89 ; \mathrm{N}, 7.79$.

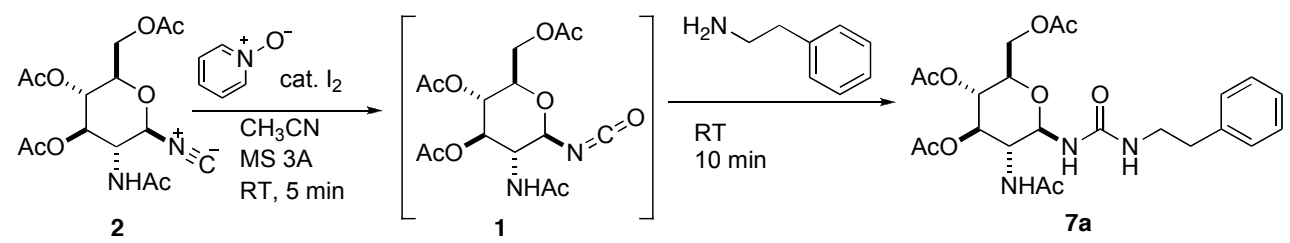

Synthesis of urea glycoside 7a. To a solution of pyridine $N$-oxide ( $24 \mathrm{mg}, 0.25$ $\mathrm{mmol})$ and powdered molecular sieves $3 \mathrm{~A}(60 \mathrm{mg})$ in acetonitrile $(2.0 \mathrm{ml})$ under argon atmosphere was added $N$-acetylglucosyl isonitrile 2 (30 $\mathrm{mg}, 0.084 \mathrm{mmol})$ and iodine (1.5 mg, $7.0 \mathrm{~mol} \%$ ). After being stirred at room temperature for $5 \mathrm{~min}$, phenethylamine $(0.02 \mathrm{ml}, 0.17 \mathrm{mmol})$ was added. The resulting reaction mixture was stirred at room temperature for $10 \mathrm{~min}$, and then filtered on Super Cell. The filtrate was poured into saturated aqueous $\mathrm{NaHSO}_{3}$ solution, and aqueous layer was extracted with AcOEt. The combined organic layers were washed with brine, dried $\left(\mathrm{Na}_{2} \mathrm{SO}_{4}\right)$ and then concentrated under reduced pressure. The resulting residue was purified by silica gel chromatography (15:1 AcOEt/MeOH) to afford $N$-acetylglucosyl urea 7a (38 mg, 92\%) as a white solid: $\mathrm{mp} 216{ }^{\circ} \mathrm{C}(\mathrm{dec}.) ;[\alpha]_{\mathrm{D}}{ }^{16}=-9.6\left(c 0.50, \mathrm{CHCl}_{3}\right)$; IR $(\mathrm{KBr})$ $v_{\max } 3334,1747,1653 \mathrm{~cm}^{-1} ;{ }^{1} \mathrm{H}$ NMR (400 MHz, $\left.\mathrm{CDCl}_{3}\right) \delta 1.92(3 \mathrm{H}, \mathrm{s}), 2.04(3 \mathrm{H}, \mathrm{s})$, $2.06(3 \mathrm{H}, \mathrm{s}), 2.08(3 \mathrm{H}, \mathrm{s}), 2.77(2 \mathrm{H}, \mathrm{td}, \mathrm{J}=7.0,2.0), 3.40(2 \mathrm{H}), 3.76(1 \mathrm{H}, \mathrm{ddd}, J=10.0$, 4.5, 2.0), $4.08(1 \mathrm{H}), 4.08(1 \mathrm{H}, \mathrm{dd}, J=12.5,2.0), 4.31(1 \mathrm{H}, \mathrm{dd}, J=12.5,4.5), 4.98(1 \mathrm{H}$, br), $5.06(1 \mathrm{H}, \mathrm{t}, J=8.5), 5.09(1 \mathrm{H}, \mathrm{t}, J=8.5), 5.11(1 \mathrm{H}, \mathrm{t}, J=7.5), 6.01(1 \mathrm{H}, \mathrm{d}, J=8.5)$, $6.34(1 \mathrm{H}, \mathrm{d}, J=8.5), 7.15-7.32(5 \mathrm{H}) ;{ }^{13} \mathrm{C} \mathrm{NMR}\left(100 \mathrm{MHz}, \mathrm{CDCl}_{3}\right) \delta 20.6,20.7,20.7$, 23.1, 36.1, 41.6, 53.4, 62.0, 68.1, 73.1, 73.2, 81.7, 126.4, 128.5, 128.7, 138.8, 156.8, 169.3, 170.7, 171.6, 171.8. Anal. Calcd for $\mathrm{C}_{23} \mathrm{H}_{31} \mathrm{~N}_{3} \mathrm{O}_{9}$ : C, 55.98; H, 6.33; N, 8.51. Found: C, 55.66; H, 6.35; N, 8.62. 


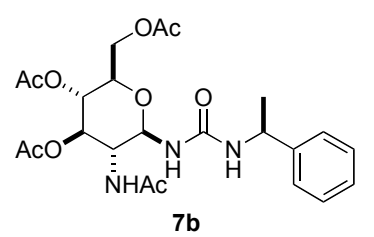

mp $270{ }^{\circ} \mathrm{C}(\mathrm{dec}) ;[\alpha]_{\mathrm{D}}{ }^{16}=-29.0\left(c 0.50, \mathrm{CHCl}_{3}\right) ; \mathrm{IR}(\mathrm{KBr}) v_{\max }$ $1746,1649 \mathrm{~cm}^{-1} ;{ }^{1} \mathrm{H}$ NMR $\left(400 \mathrm{MHz}, \mathrm{CDCl}_{3}\right) \delta 1.41(3 \mathrm{H}, \mathrm{d}, J=$ 7), $1.80(3 \mathrm{H}, \mathrm{s}), 2.03(3 \mathrm{H}, \mathrm{s}), 2.05(3 \mathrm{H}, \mathrm{s}), 2.08(3 \mathrm{H}, \mathrm{s}), 3.71(1 \mathrm{H}$, ddd, $\mathrm{J}=9.0,4.5,2.0), 4.06(2 \mathrm{H}), 4.28(1 \mathrm{H}, \mathrm{dd}, J=12.0,4.0)$, $4.87(1 \mathrm{H}, \mathrm{br}), 5.08(3 \mathrm{H}), 5.30(1 \mathrm{H}, \mathrm{br}), 5.99(1 \mathrm{H}, \mathrm{br}), 6.25(1 \mathrm{H}, \mathrm{br}), 7.19-7.30(5 \mathrm{H}) ;{ }^{13} \mathrm{C}$ NMR (100 MHz, $\left.\mathrm{CDCl}_{3}\right)$ \& 20.5, 20.68, 20.74, 22.9, 23.0, 49.5, 53.5, 62.1, 68.3, 73.1, 73.2, 81.5, 125.7, 127.0, 128.5, 144.4, 156.1, 169.3, 170.7, 171.4, 171.9. Anal. Calcd for $\mathrm{C}_{23} \mathrm{H}_{31} \mathrm{~N}_{3} \mathrm{O}_{9}$ : C, 55.98; H, 6.33; N, 8.51. Found: C, 55.69; H, 6.43; N, 8.67.

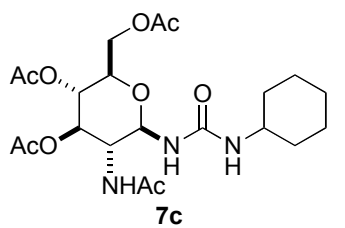

mp $275{ }^{\circ} \mathrm{C}(\mathrm{dec}.) ;[\alpha]_{\mathrm{D}}{ }^{21}=-9.2\left(\right.$ c $\left.0.50, \mathrm{CHCl}_{3}\right)$; IR $(\mathrm{KBr}) v_{\max }$ $3332,1741,1647 \mathrm{~cm}^{-1} ;{ }^{1} \mathrm{H}$ NMR $\left(400 \mathrm{MHz}, \mathrm{CDCl}_{3}\right) \delta 1.03-1.70$ (10H), $1.95(3 \mathrm{H}, \mathrm{s}), 2.04(3 \mathrm{H}, \mathrm{s}), 2.06(3 \mathrm{H}, \mathrm{s}), 2.09(3 \mathrm{H}, \mathrm{s}), 3.76$ (1H, ddd, $J=10.0,4.0,2.0), 4.09$ (1H, dd, $J=12.5,2.0), 4.14$ (1H, t, $J=10.0), 4.32$ $(1 \mathrm{H}, \mathrm{dd}, J=12.5,4.0), 4.56$ (1H, d, $J=8.0), 5.04(1 \mathrm{H}, \mathrm{dd}, J=10.0,8.5), 5.07(1 \mathrm{H}, \mathrm{t}, J$ $=10.0), 5.12(1 \mathrm{H}, \mathrm{t}, J=9.0), 5.85(1 \mathrm{H}, \mathrm{d}, J=8.5), 6.15(1 \mathrm{H}, \mathrm{d}, J=8.0) ;{ }^{13} \mathrm{C}$ NMR $(100$ $\left.\mathrm{MHz}, \mathrm{CDCl}_{3}\right) \delta$ d 20.6, 20.7, 20.8, 23.2, 24.8, 25.5, 33.6, 49.2, 53.6, 61.9, 67.8, 73.1, 82.2, 155.8, 169.3, 170.8, 171.8, 172.0. Anal. Calcd for $\mathrm{C}_{21} \mathrm{H}_{33} \mathrm{~N}_{3} \mathrm{O}_{9}$ : C, 53.49; H, 7.05; N, 8.91. Found: C, 53.49; H, 7.05; N, 8.91.

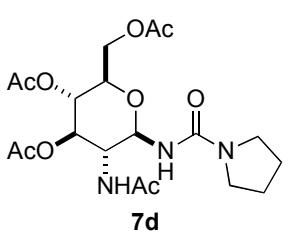

mp 187-188 ${ }^{\circ} \mathrm{C} ;[\alpha]_{\mathrm{D}}{ }^{21}=-21.0\left(c 1.00, \mathrm{CHCl}_{3}\right) ; \mathrm{IR}(\mathrm{KBr}) v_{\max } 3379$, 1748, $1649 \mathrm{~cm}^{-1} ;{ }^{1} \mathrm{H}$ NMR (400 MHz, $\left.\mathrm{CDCl}_{3}\right) \delta 1.87$ (4H, br), 1.95 $(3 \mathrm{H}, \mathrm{s}), 2.04(3 \mathrm{H}, \mathrm{s}), 2.07(3 \mathrm{H}, \mathrm{s}), 2.09(3 \mathrm{H}, \mathrm{s}), 3.34(4 \mathrm{H}, \mathrm{br}), 3.78$ (1H, ddd, $J=9.5,4.0,2.0), 4.10(1 \mathrm{H}, \mathrm{dd}, J=12.5,2.0), 4.13(1 \mathrm{H}, \mathrm{td}$, $J=10.0,8.5), 4.31(1 \mathrm{H}, \mathrm{dd}, J=12.5,4.0), 5.05(1 \mathrm{H}, \mathrm{dd}, J=10.0,8.0), 5.08(1 \mathrm{H}, \mathrm{t}, J=$ 9.0), $5.13(1 \mathrm{H}, \mathrm{t}, J=9.5), 6.06(1 \mathrm{H}, \mathrm{d}, J=8.0), 6.22(1 \mathrm{H}, \mathrm{br}) ;{ }^{13} \mathrm{C}$ NMR $(100 \mathrm{MHz}$, $\left.\mathrm{CDCl}_{3}\right) \delta$ 20.5, 20.68, 20.69, 23.1, 25.4, 45.5, 53.3, 61.9, 68.1, 72.8, 73.0, 82.0, 155.2, 169.3, 170.7, 171.6, 172.1. Anal. Calcd for $\mathrm{C}_{19} \mathrm{H}_{29} \mathrm{~N}_{3} \mathrm{O}_{9}$ : C, 51.46; H, 6.59; N, 9.48. Found: C, 51.26; H, 6.49; N, 9.12. 


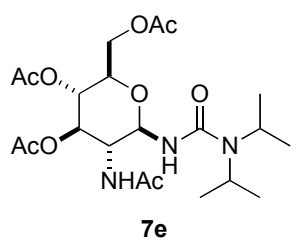

mp 52-53 ${ }^{\circ} \mathrm{C} ;[\alpha]_{\mathrm{D}}{ }^{17}=-16.4\left(\right.$ c $\left.1.00, \mathrm{CHCl}_{3}\right) ; \mathrm{IR}(\mathrm{KBr}) v_{\max } 1749$, $1644 \mathrm{~cm}^{-1} ;{ }^{1} \mathrm{H}$ NMR $\left(400 \mathrm{MHz}, \mathrm{CDCl}_{3}\right) \delta 1.23(6 \mathrm{H}, \mathrm{d}, J=7.0), 1.26$ (6H, d, $J=7.0), 1.93(3 \mathrm{H}, \mathrm{s}), 2.04(3 \mathrm{H}, \mathrm{s}), 2.07(3 \mathrm{H}, \mathrm{s}), 2.10(3 \mathrm{H}, \mathrm{s})$, $3.65(1 \mathrm{H}, \mathrm{q}, J=7.0), 3.67(1 \mathrm{H}, \mathrm{q}, J=7.0) 3.74(1 \mathrm{H}, \mathrm{ddd}, J=10.0$, 4.0, 2.0), 4.08 (1H, dd, $J=12.5,2.0), 4.16(1 \mathrm{H}, \mathrm{td}, J=10.0,8.0), 4.34$ (1H, dd, $J=12.5$, 4.0), 5.04 (1H, dd, $J=10.0,9.0), 5.11$ (1H, dd, $J=10.0,9.0), 5.15$ (1H, t, $J=10.0$ ), $5.88(1 \mathrm{H}, \mathrm{d}, J=8.0), 6.06(1 \mathrm{H}, \mathrm{br}, J=8.0) ;{ }^{13} \mathrm{C} \mathrm{NMR}\left(100 \mathrm{MHz}, \mathrm{CDCl}_{3}\right) \delta 20.6,20.7$, 21.1, 21.2, 23.0, 46.0, 53.3, 61.9, 68.0, 73.1, 73.2, 82.2, 155.4, 169.3, 170.7, 171.7, 171.7. Anal. Calcd for $\mathrm{C}_{21} \mathrm{H}_{35} \mathrm{~N}_{3} \mathrm{O}_{9}$ : C, 53.27; H, 7.45; N, 8.87. Found: C, 53.18; $\mathrm{H}$, $7.70 ; \mathrm{N}, 8.51$.

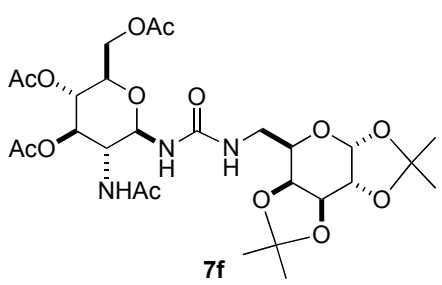

mp 204-205 ${ }^{\circ} \mathrm{C} ;[\alpha]_{\mathrm{D}}{ }^{21}=-31.5\left(c 1.00, \mathrm{CHCl}_{3}\right)$; IR $(\mathrm{KBr})$ $v_{\max } 3342,1748,1660 \mathrm{~cm}^{-1} ;{ }^{1} \mathrm{H}$ NMR $\left(400 \mathrm{MHz}, \mathrm{CDCl}_{3}\right) \delta$ $1.32(3 \mathrm{H}, \mathrm{s}), 1.33(3 \mathrm{H}, \mathrm{s}), 1.44(3 \mathrm{H}, \mathrm{s}), 1.49(3 \mathrm{H}, \mathrm{s}), 1.95$ $(3 \mathrm{H}, \mathrm{s}), 2.04(3 \mathrm{H}, \mathrm{s}), 2.06(3 \mathrm{H}, \mathrm{s}), 2.08(3 \mathrm{H}, \mathrm{s}), 3.20(1 \mathrm{H}$, br), $3.56(1 \mathrm{H}, \mathrm{br}), 3.74(1 \mathrm{H}, \mathrm{ddd}, J=10.0,4.0,2.0), 3.83(1 \mathrm{H}, \mathrm{br}), 4.06(1 \mathrm{H}, \mathrm{dd}, J=$ 12.0, 2.0), $4.13(1 \mathrm{H}), 4.19$ (1H, dd, $J=8.0,1$.), $4.28(2 \mathrm{H}), 4.58(1 \mathrm{H}, \mathrm{dd}, J=8.0,2.0)$, $5.03(1 \mathrm{H}, \mathrm{t}, J=10.0), 5.09(1 \mathrm{H}, \mathrm{t}, J=10.0), 5.12(1 \mathrm{H}, \mathrm{t}, J=9.5), 5.22(1 \mathrm{H}, \mathrm{br}) 5.50(1 \mathrm{H}$, d, $J=5.0), 6.02(1 \mathrm{H}, \mathrm{br}), 6.15(1 \mathrm{H}, \mathrm{br}) ;{ }^{13} \mathrm{C}$ NMR $\left(100 \mathrm{MHz}, \mathrm{CDCl}_{3}\right) \delta 20.6,20.7,23.2$, $24.3,24.9,25.9,26.0,40.7,53.4,61.9,67.0,68.0,70.5,70.7,71.5,73.0,73.2,81.9$, 96,1, 108.7, 109.4, 156.9, 169.3, 170.7, 171.7, 171.7. Anal. Calcd for $\mathrm{C}_{27} \mathrm{H}_{40} \mathrm{~N}_{2} \mathrm{O}_{14}$ : C, 51.34; H, 6.54; N, 6.65. Found: C, 51.06; H, 6.76; N, 6.46. 


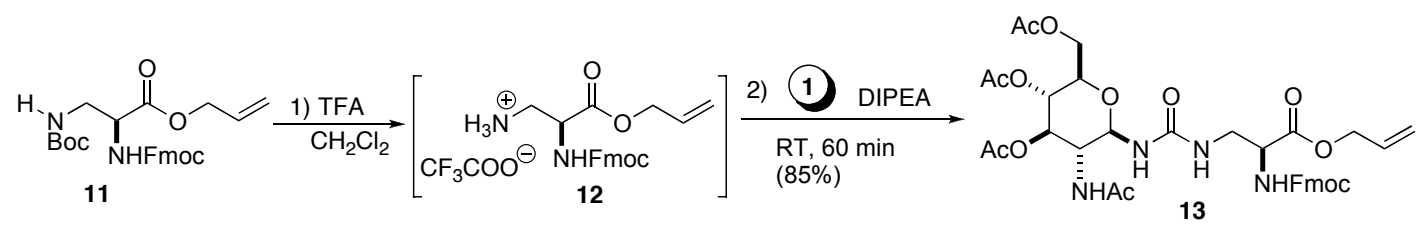

Synthesis of urea-linked Fmoc-protected $N$-acetyl-D-glucosamine amino acid conjugate 13. A solution of Boc-protected $\alpha, \beta$-diamino acid 11 (40 mg, $0.086 \mathrm{mmol})$ in $\mathrm{CH}_{2} \mathrm{Cl}_{2}(1.0 \mathrm{ml})$ was treated with TFA $(90 \mu \mathrm{l}, 1.17 \mathrm{mmol})$ at room temperature for 15 min, and then the reaction mixture was concentrated. The resulting TFA sat 12 was dissolved in a mixture of diisopropylethylamine ( $44 \mu \mathrm{l}, 0.34 \mathrm{mmol})$ and acetonitrile $(1.0$ $\mathrm{ml}$ ), and then treated with a solution of isocyanate $\mathbf{1}$ [prepared from $\mathrm{N}$-acetylglucosyl isonitrile 2 (61 $\mathrm{mg}, 0.17 \mathrm{mmol}$ ), pyridine $N$-oxide (49 $\mathrm{mg}, 0.51 \mathrm{mmol}$ ), iodine ( $3 \mathrm{mg}, 7$ mol\%), powdered molecular sieves 3A $(120 \mathrm{mg})$, and acetonitrile $(2.0 \mathrm{ml})]$. After stirring for $1 \mathrm{~h}$, the reaction mixture was filtered on Super Cell. The filtrate was poured into saturated aqueous $\mathrm{NaHSO}_{3}$ solution, and aqueous layer was extracted with AcOEt. The combined organic layers were washed with brine, dried $\left(\mathrm{Na}_{2} \mathrm{SO}_{4}\right)$ and then concentrated under reduced pressure. The resulting residue was purified by silica gel chromatography (10:1 AcOEt/hexane) to afford $13(55 \mathrm{mg}, 85 \%)$ as a white solid:

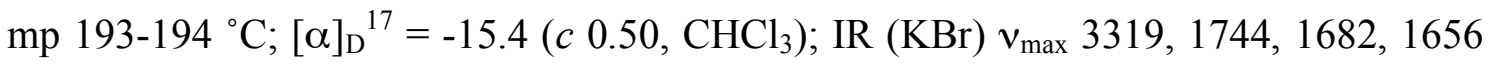
$\mathrm{cm}^{-1} ;{ }^{1} \mathrm{H}$ NMR (400MHz, CD $\left.{ }_{3} \mathrm{OD}\right) \delta 1.87(3 \mathrm{H}, \mathrm{s}), 1.96(3 \mathrm{H}, \mathrm{s}), 1.98(3 \mathrm{H}, \mathrm{s}), 1.99(3 \mathrm{H}$, s), $3.39(1 \mathrm{H}, \mathrm{dd}, J=14.0,8.0), 3.65(1 \mathrm{H}, \mathrm{dd}, J=14.0,5.0), 3.76(1 \mathrm{H}, \mathrm{ddd}, J=10.0,4.0$, 2.0), 3.98 (1H, t, $J=10.0) 3.99$ (1H, dd, $J=12.0,2.0), 4.20(1 \mathrm{H}, \mathrm{t}, J=7.0), 4.23(1 \mathrm{H}$, $\mathrm{dd}, J=12.0,4.0), 4.29$ (1H, dd, $J=10.0,7.0), 4.34(1 \mathrm{H}, \mathrm{dd}, J=8.0,5.0), 4.37(1 \mathrm{H}, \mathrm{dd}$, $J=10.0,7.0), 4.62(1 \mathrm{H}, \mathrm{dd}, J=5.5,1.0), 4.95(1 \mathrm{H}, \mathrm{t}, J=10.0), 4.99(1 \mathrm{H}, \mathrm{d}, J=10.0)$, $5.14(1 \mathrm{H}, \mathrm{dd}, J=10.5,9.5), 5.20$ (1H, ddd, $J=12.0,5.5,1.0), 5.32$ (1H, dd, $J=17.0$, 1.0), $5.93(1 \mathrm{H}$, ddt, $J=17.0,11.0,5.0), 7.28-7.40(4 \mathrm{H}), 7.63-7.67(2 \mathrm{H}), 7.79(2 \mathrm{H}, \mathrm{d}, J=$ 7.5); ${ }^{13} \mathrm{C}$ NMR (100 MHz, DMSO) $\delta$ 20.3, 20.4, 20.5, 20.9, 21.0, 22.6, 46.6, 51.8, 54.6, $61.9,65.0,65.7,68.6,71.7,73.5,80.0,117.6,120.2$, 125.1, 127.1, 127.7, 132.3, 140.7, 143.7, 143.8, 156.1, 156.8, 169.3, 169.5, 170.1, 170.4. Anal. Calcd for $\mathrm{C}_{36} \mathrm{H}_{42} \mathrm{~N}_{4} \mathrm{O}_{13}: \mathrm{C}$, 58.53; H, 5.73; N, 7.58. Found: C, 58.55; H, 5.47; N, 7.22. 


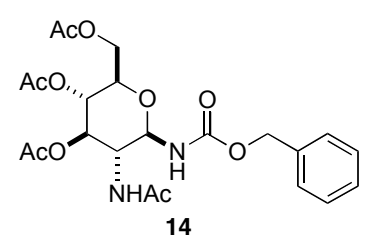

$\operatorname{mp} 198-200{ }^{\circ} \mathrm{C} ;[\alpha]_{\mathrm{D}}^{21}=-18.0\left(c 0.50, \mathrm{CHCl}_{3}\right)$; IR $(\mathrm{KBr}) v_{\max }$ 3336, 1746, 1531, $1245 \mathrm{~cm}^{-1} ;{ }^{1} \mathrm{H}$ NMR (400 MHz, $\left.\mathrm{CDCl}_{3}\right) \delta 1.91$ $(3 \mathrm{H}, \mathrm{s}), 2.04(3 \mathrm{H}, \mathrm{s}), 2.06(3 \mathrm{H}, \mathrm{s}), 2.09(3 \mathrm{H}, \mathrm{s}), 3.74(1 \mathrm{H}, \mathrm{br}), 4.09$ $(1 \mathrm{H}, \mathrm{dd}, J=12.0,2.0), 4.15(1 \mathrm{H}, \mathrm{t}, J=9.5), 4.29(1 \mathrm{H}, \mathrm{dd}, 12.5$, 4.0), $4.87(1 \mathrm{H}, \mathrm{t}, J=9.5), 5.04(1 \mathrm{H}, \mathrm{t}, J=9.5), 5.10(2 \mathrm{H}, \mathrm{s}), 5.12(1 \mathrm{H}, \mathrm{t}, J=9.5), 5.95$ $(1 \mathrm{H}, \mathrm{d}, J=8.0), 6.25(1 \mathrm{H}, \mathrm{d}, J=8.0), 7.30-7.38(5 \mathrm{H}) ;{ }^{13} \mathrm{C} \mathrm{NMR}\left(100 \mathrm{MHz}, \mathrm{CDCl}_{3}\right) \delta$ $20.5,20.7,23.0,53.0,61.7,67.1,67.8,73.0,73.2,82.6,127.9,128.1,128.4,135.9$, 155.9, 169.2, 170.7, 171.6, 171.7. Anal. Calcd for $\mathrm{C}_{22} \mathrm{H}_{28} \mathrm{~N}_{2} \mathrm{O}_{10}: \mathrm{C}, 55.00 ; \mathrm{H}, 5.87 ; \mathrm{N}$, 5.83. Found: C, 55.09; H, 5.67; N, 6.00.

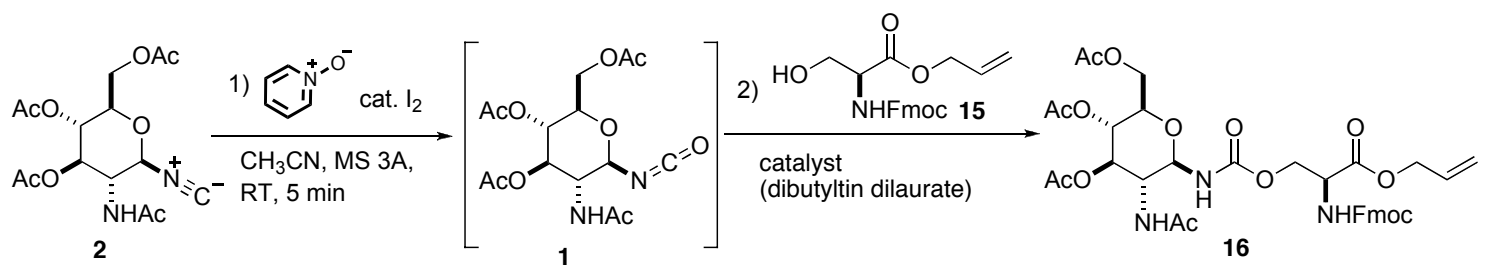

\section{Synthesis of carbamate-linked Fmoc-protected $N$-acetyl-D-glucosamine amino} acid conjugate 16. To a solution of pyridine $N$-oxide $(75 \mathrm{mg}, 0.78 \mathrm{mmol})$ and powdered molecular sieves $3 \mathrm{~A}(180 \mathrm{mg})$ in acetonitrile $(5.0 \mathrm{ml})$ under argon atmosphere was added isonitrile $2(93 \mathrm{mg}, 0.26 \mathrm{mmol})$ and iodine $(5 \mathrm{mg}, 7 \mathrm{~mol} \%)$. After stirring at room temperature for $5 \mathrm{~min}$, serine derivative 15 (32 $\mathrm{mg}, 0.087 \mathrm{mmol})$ and dibutyltin (IV) dilaurate $(9 \mathrm{mg}, 0.017 \mathrm{mmol})$ was added. After being stirred at room temperature for $7 \mathrm{~h}$, the reaction mixture was filtered on Super Cell. The filtrate was poured into saturated aqueous $\mathrm{NaHSO}_{3}$ solution, and aqueous layer was extracted with AcOEt. The combined organic layers were washed with brine, dried $\left(\mathrm{Na}_{2} \mathrm{SO}_{4}\right)$ and then concentrated under reduced pressure. The resulting residue was purified by silica gel chromatography (3:1 AcOEt/hex) to afford $16(52 \mathrm{mg}, 81 \%)$ as a white solid: $\operatorname{mp} 184-185{ }^{\circ} \mathrm{C} ;[\alpha]_{\mathrm{D}}{ }^{21}=-5.2\left(c 0.50, \mathrm{CHCl}_{3}\right)$; IR (KBr) $v_{\max } 3334,1745,1661,1532$, $1241 \mathrm{~cm}^{-1} ;{ }^{1} \mathrm{H}$ NMR $\left(400 \mathrm{MHz}, \mathrm{CDCl}_{3}\right) \oint 1.94(3 \mathrm{H}, \mathrm{s}), 2.05(3 \mathrm{H}, \mathrm{s}), 2.07(3 \mathrm{H}, \mathrm{s}), 2.08$ $(3 \mathrm{H}, \mathrm{s}), 3.72(1 \mathrm{H}, \mathrm{br}), 4.09(1 \mathrm{H}, \mathrm{dd}, J=16.0,13.0), 4.13(1 \mathrm{H}, \mathrm{t}, J=7.0), 4.24(2 \mathrm{H}, \mathrm{t}, J=$ 
8.0) $4.28(1 \mathrm{H}, \mathrm{dd}, J=13.0,4.0), 4.34(1 \mathrm{H}, \mathrm{dd}, J=13.0,7.0), 4.41(1 \mathrm{H}, \mathrm{dd}, J=12.5$, 2.0), 4.42 (1H, dd, $J=11.0,7.0), 4.50$ (1H, dd, $J=11.0,4.0), 4.64$ (1H, br), 4.67 (1H, d, $J=5.0), 4.82(1 \mathrm{H}, \mathrm{t}, J=9.0), 5.04(1 \mathrm{H}, \mathrm{t}, J=10.0), 5.12(1 \mathrm{H}, \mathrm{t}, J=9.5), 5.29(1 \mathrm{H}, \mathrm{d}, J$ $=10.5), 5.34(1 \mathrm{H}, \mathrm{d}, J=18.0), 5.76(1 \mathrm{H}, \mathrm{d}, J=9.0), 5.89(1 \mathrm{H}, \mathrm{br}), 5.93(1 \mathrm{H}, \mathrm{d}, J=9.0)$, $6.30(1 \mathrm{H}, \mathrm{d}, J=9.0), 7.32(2 \mathrm{H}, \mathrm{br}), 7.41(2 \mathrm{H}, \mathrm{t}, J=7.5), 7.61(2 \mathrm{H}, \mathrm{d}, J=7.0), 7.76(2 \mathrm{H}$, d, $J=8.0) ;{ }^{13} \mathrm{C}$ NMR (100 MHz, DMSO) $\delta$ 20.3, 20.4, 20.5, 22.7, 46.6, 52.1, 53.4, 61.8, $63.1,65.3,65.9,68.6,71.7,73.5,80.0,117.8,120.2$, 125.2, 127.1, 127.7, 132.2, 140.7, 143.7, 143.8, 155.4, 156.0, 169.3, 169.4, 170.0. Anal. Calcd for $\mathrm{C}_{36} \mathrm{H}_{41} \mathrm{~N}_{3} \mathrm{O}_{14}$ : C, 58.45; H, 5.59; N, 5.68. Found: C, 58.68; H, 5.70; N, 5.74.

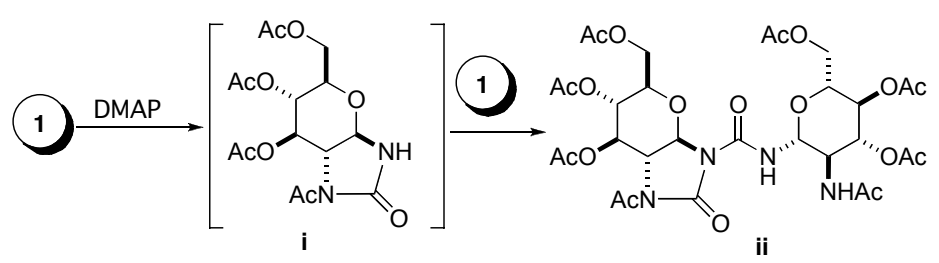

Dimerization product in reference (16). $\mathrm{mp} 180{ }^{\circ} \mathrm{C}(\mathrm{dec}) ;[\alpha]_{\mathrm{D}}{ }^{17}=-52.7(c$ 1.00, $\left.\mathrm{CHCl}_{3}\right)$; IR (KBr) $v_{\max } 3326,1743,1659 \mathrm{~cm}^{-1} ;{ }^{1} \mathrm{H}$ NMR $\left(400 \mathrm{MHz}, \mathrm{CDCl}_{3}\right) \delta 1.96(3 \mathrm{H}$, s), $2.05(3 \mathrm{H}, \mathrm{s}), 2.07(6 \mathrm{H}, \mathrm{s}), 2.08(3 \mathrm{H}, \mathrm{s}), 2.09(3 \mathrm{H}, \mathrm{s}), 2.11(3 \mathrm{H}, \mathrm{s}), 2.48(3 \mathrm{H}, \mathrm{s}), 3.73$ (1H, ddd, $J=10.0,4.2,2.0), 3.76(1 \mathrm{H}, \mathrm{dd}, J=10.0,8.5), 4.04(1 \mathrm{H}, \mathrm{td}, J=10.0,4.0)$, 4.10 (1H, dd, $J=12.5,2.0), 4.20-4.30$ (4H), 4.97 (1H, d, $J=8.5$ ), 4.99 (1H, dd, $J=10.0$, 8.5), 5.06 (1H, t, $J=10.0), 5.14$ (1H, t, $J=10.0), 5.25$ (1H, dd, $J=10.0,8.5), 5.32(1 \mathrm{H}$, $\mathrm{t}, J=9.0), 5.92(1 \mathrm{H}, \mathrm{d}, J=8.0), 8.61(1 \mathrm{H}, \mathrm{d}, J=9.0) ;{ }^{13} \mathrm{C} \mathrm{NMR}\left(100 \mathrm{MHz}, \mathrm{CDCl}_{3}\right) \delta$ 20.5, 20.7, 23.1, 25.6, 52.8, 58.8, 61.6, 61.7, 67.7, 68.2, 72.7, 73.3, 81.1, 83.6, 151.7, $152.8,169.1,169.2,170.5,170.7,170.9,171.5,171.8,172.3$. Anal. Calcd for $\mathrm{C}_{30} \mathrm{H}_{40} \mathrm{~N}_{4} \mathrm{O}_{18}: \mathrm{C}, 48.39 ; \mathrm{H}, 5.41 ; \mathrm{N}, 7.52$. Found: $\mathrm{C}, 48.39 ; \mathrm{H}, 5.43 ; \mathrm{N}, 7.23$. 


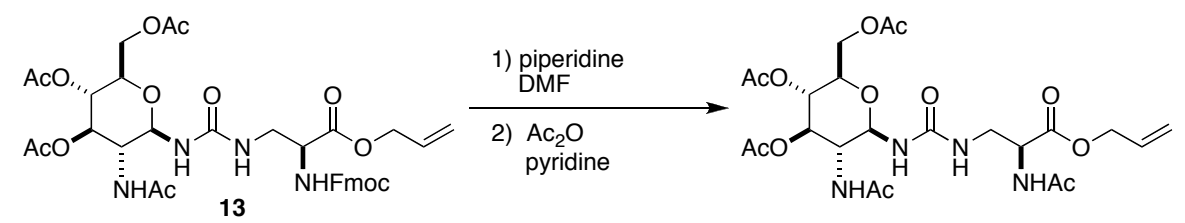

Fmoc-deprotection of 13 in reference (19). To a solution of urea-tethered amino acid conjugate $13(10 \mathrm{mg}, 0.013 \mathrm{mmol})$ in DMF $(0.90 \mathrm{ml})$ was added piperidine $(120 \mu \mathrm{l}$, $1.22 \mathrm{mmol}$ ). After stirring at room temperature for $10 \mathrm{~min}$, the reaction mixture was concentrated under vacuum to afford the crude amine, which was dissolved in a mixture of pyridine $(0.60 \mathrm{ml})$ and acetic anhydride $(0.20 \mathrm{ml})$. After stirring at room temperature for $30 \mathrm{~min}$, concentration of the reaction mixture under reduced pressure gave the residue, which was purified by silica gel chromatography (10:1 AcOEt/MeOH) to afford the compound in reference (19) $(7 \mathrm{mg}, 93 \%): \mathrm{mp} 224{ }^{\circ} \mathrm{C}(\mathrm{dec}.) ;[\alpha]_{\mathrm{D}}{ }^{26}=-24.5(c 0.31$, $\left.\mathrm{CHCl}_{3}\right)$; IR (KBr) $v_{\max } 3306,1746,1654 \mathrm{~cm}^{-1} ;{ }^{1} \mathrm{H} \mathrm{NMR}\left(400 \mathrm{MHz}, \mathrm{CDCl}_{3}\right) \delta 1.97(3 \mathrm{H}$, s), $2.03(3 \mathrm{H}, \mathrm{s}), 2.04(3 \mathrm{H}, \mathrm{s}), 2.06(3 \mathrm{H}, \mathrm{s}), 2.08(3 \mathrm{H}, \mathrm{s}), 3.57(2 \mathrm{H}), 3.79(1 \mathrm{H}, \mathrm{ddd}, J=$ 9.0, 4.5, 2.0), 4.09 (1H, t, $J=9.0), 4.10(1 \mathrm{H}, \mathrm{dd}, J=12.5,2.0), 4.29$ (1H, dd, $J=12.5$, 4.5), $4.64(3 \mathrm{H}), 5.06(2 \mathrm{H}, \mathrm{d}, J=7.0), 5.10-5.16(2 \mathrm{H}), 5.26(1 \mathrm{H}, \mathrm{dd}, J=10.0,1.0), 5.12$ $(1 \mathrm{H}, \mathrm{t}, J=9.0), 5.33(1 \mathrm{H}, \mathrm{dtd}, J=17.5,2.0,1.0), 5.77(1 \mathrm{H}, \mathrm{t}, J=6.0), 5.91(1 \mathrm{H}, \mathrm{ddt}, J=$ $17.5,10.0,6.0), 6.12(1 \mathrm{H}, \mathrm{d}, J=9.0), 6.53(1 \mathrm{H}, \mathrm{d}, J=9.0), 7.19(1 \mathrm{H}, \mathrm{d}, J=7.5) ; \quad{ }^{1} \mathrm{H}$ NMR (400 MHz, CD $\left.{ }_{3} \mathrm{OD}\right) \delta 1.90(3 \mathrm{H}, \mathrm{s}), 1.97(3 \mathrm{H}, \mathrm{s}), 1.98(3 \mathrm{H}, \mathrm{s}), 2.00(3 \mathrm{H}, \mathrm{s}), 2.02$ (3H, s), 3.37 (1H, dd, $J=9.0,7.5), 3.61(1 \mathrm{H}, \mathrm{dd}, J=9.0,5.0), 3.79$ (1H, ddd, $J=10.0$, 4.0, 2.0), 3.99 (1H, t, $J=10.0), 4.06(1 \mathrm{H}, \mathrm{dd}, J=12.5,2.0), 4.25(1 \mathrm{H}, \mathrm{dd}, J=12.5,4.0)$, $4.51(1 \mathrm{H}, \mathrm{dd}, J=7.5,5.0), 4.61-4.63(2 \mathrm{H}), 4.97(1 \mathrm{H}, \mathrm{t}, J=10.0), 4.99(1 \mathrm{H}, \mathrm{d}, J=10.0)$, $5.16(1 \mathrm{H}, \mathrm{t}, J=10.0), 5.22(1 \mathrm{H}, \mathrm{dd}, J=11.0,1.0), 5.32(1 \mathrm{H}, \mathrm{dd}, J=17.5,1.0), 5.93(1 \mathrm{H}$, ddt, $J=17.5,11.0,5.5) ;{ }^{13} \mathrm{C} \mathrm{NMR}\left(100 \mathrm{MHz}, \mathrm{CDCl}_{3}\right) \delta 20.6,20.7,20.8,23.0,23.2$, $41.8,53.3,53.7,62.0,66.3,68.0,73.1,81.6,119.0,131.5,157.8,169.4,170.2$, 170.7, $170.8,171.6,172.1$. 


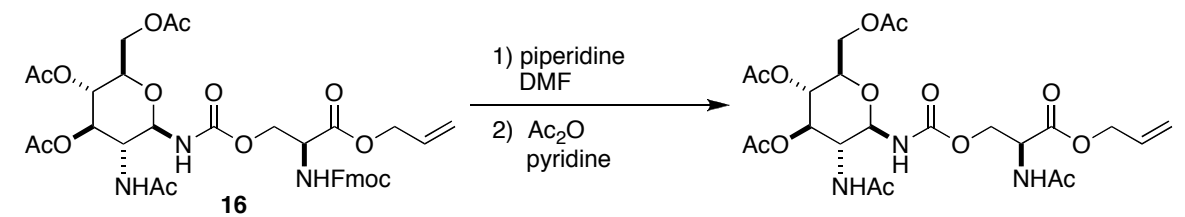

Fmoc-deprotection of 16 in reference (19). To a solution of carbamate-tethered amino acid conjugate $16(15 \mathrm{mg}, 0.020 \mathrm{mmol})$ in DMF $(0.90 \mathrm{ml})$ was added piperidine (180 $\mu \mathrm{l}, 1.8 \mathrm{mmol})$. After stirring at room temperature for $10 \mathrm{~min}$, the reaction mixture was concentrated under vacuum to afford the crude amine, which was dissolved in a mixture of pyridine $(0.90 \mathrm{ml})$ and acetic anhydride $(0.30 \mathrm{ml})$. After stirring at room temperature for $30 \mathrm{~min}$, concentration of the reaction mixture under reduced pressure gave the residue, which was purified by silica gel chromatography $(15: 1 \mathrm{AcOEt} / \mathrm{MeOH})$ to afford the the compound in reference (19) $(10 \mathrm{mg}, 88 \%): \mathrm{mp} 156-157{ }^{\circ} \mathrm{C} ;[\alpha]_{\mathrm{D}}^{25}=$ +3.7 $\left(c\right.$ 0.35, $\left.\mathrm{CHCl}_{3}\right) ; v_{\max } 3306,1746,1654,1558,1234 \mathrm{~cm}^{-1} ;{ }^{1} \mathrm{H}$ NMR (400 MHz, $\left.\mathrm{CDCl}_{3}\right) \delta 1.98(3 \mathrm{H}, \mathrm{s}), 2.04(3 \mathrm{H}, \mathrm{s}), 2.06(3 \mathrm{H}, \mathrm{s}), 2.07(3 \mathrm{H}, \mathrm{s}), 2.09(3 \mathrm{H}, \mathrm{s}), 3.75(1 \mathrm{H}$, ddd, $J=9.0,4.0,2.0), 4.09$ (1H, dd, $J=12.5,2.0), 4.13$ (1H, dd, $J=10.0,8.0), 4.30$ (1H, dd, $J=12.5,4.0), 4.35$ (1H, dd, $J=11.0,3.0), 4.48$ (1H, dd, $J=11.0,4.0), 4.66$ $(2 \mathrm{H}, \mathrm{d}, J=7.0), 4.84(1 \mathrm{H}, \mathrm{t}, J=9.0), 4.88(1 \mathrm{H}, \mathrm{dd}, J=7.0,4.0), 5.06(1 \mathrm{H}, \mathrm{t}, J=10.0)$, $5.12(1 \mathrm{H}, \mathrm{t}, J=9.0), 5.28(1 \mathrm{H}, \mathrm{dd}, J=10.0,1.0), 5.34(1 \mathrm{H}, \mathrm{dd}, J=17.0,1.0), 5.90(1 \mathrm{H}$, ddt, $J=17.0,11.0,6.0), 6.12(1 \mathrm{H}, \mathrm{d}, J=7.0), 6.33(1 \mathrm{H}, \mathrm{d}, J=9.0), 6.56(1 \mathrm{H}, \mathrm{d}, J=$ 7.5); ${ }^{13} \mathrm{C} \mathrm{NMR}\left(100 \mathrm{MHz}, \mathrm{CDCl}_{3}\right) \delta 20.6,20.7,20.8,23.06,23.14,51.9,53.2,61.7$, 65.1, 66.5, 67.6, 72.9, 73.3, 82.7, 119.2, 131.2, 155.5, 169.0, 169.3, 170.1, 170.7, 171.9, 172.0 . 


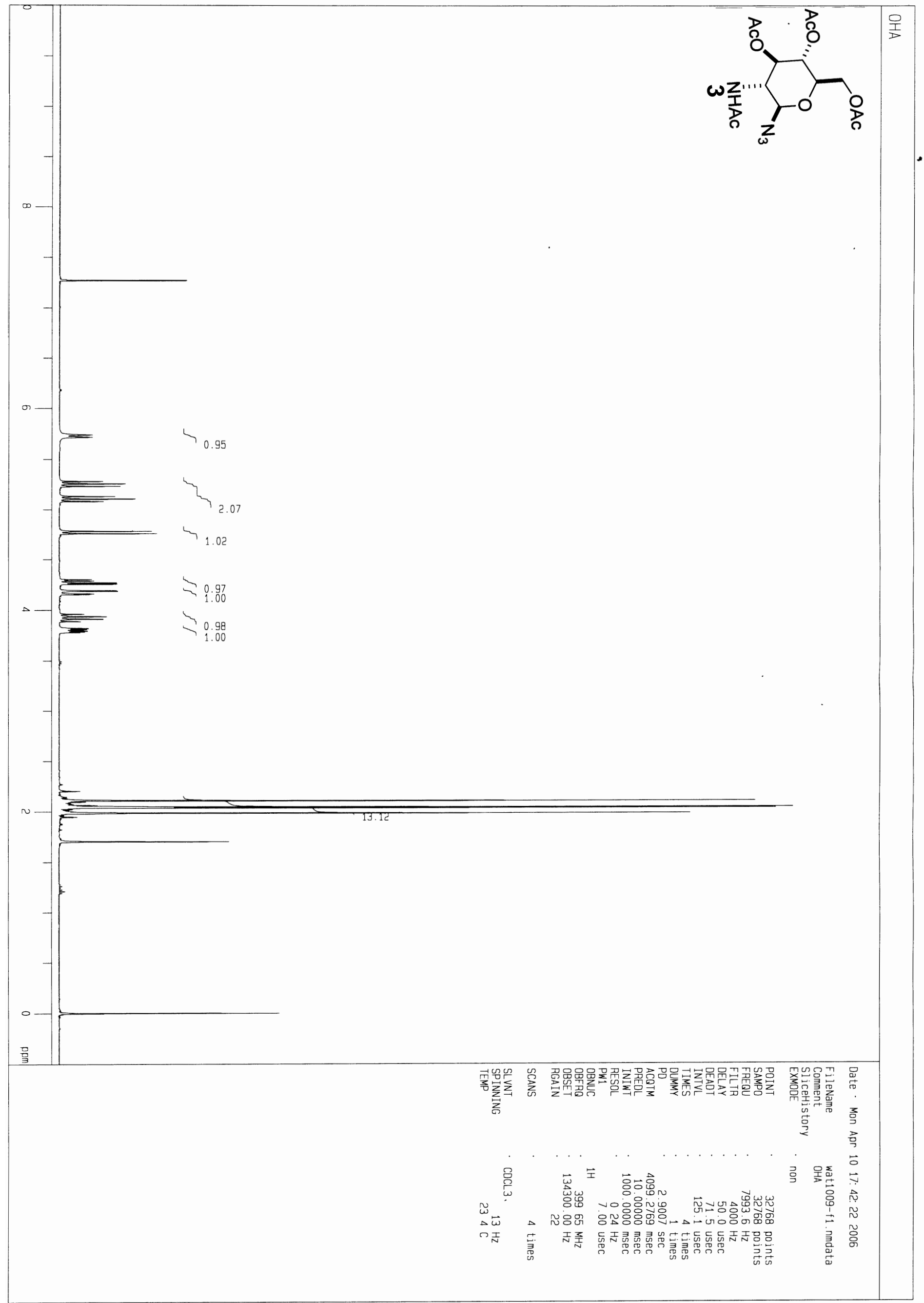




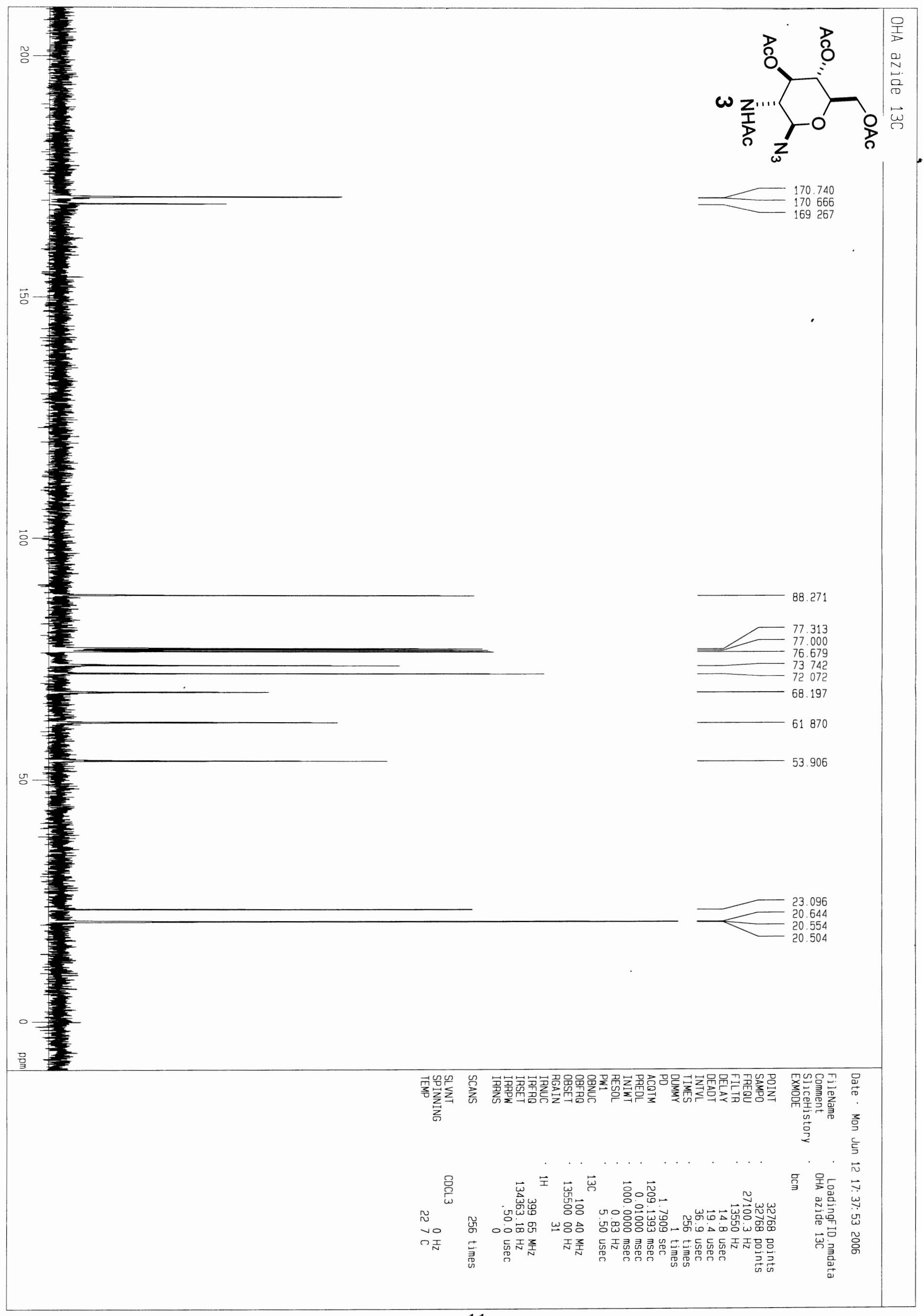




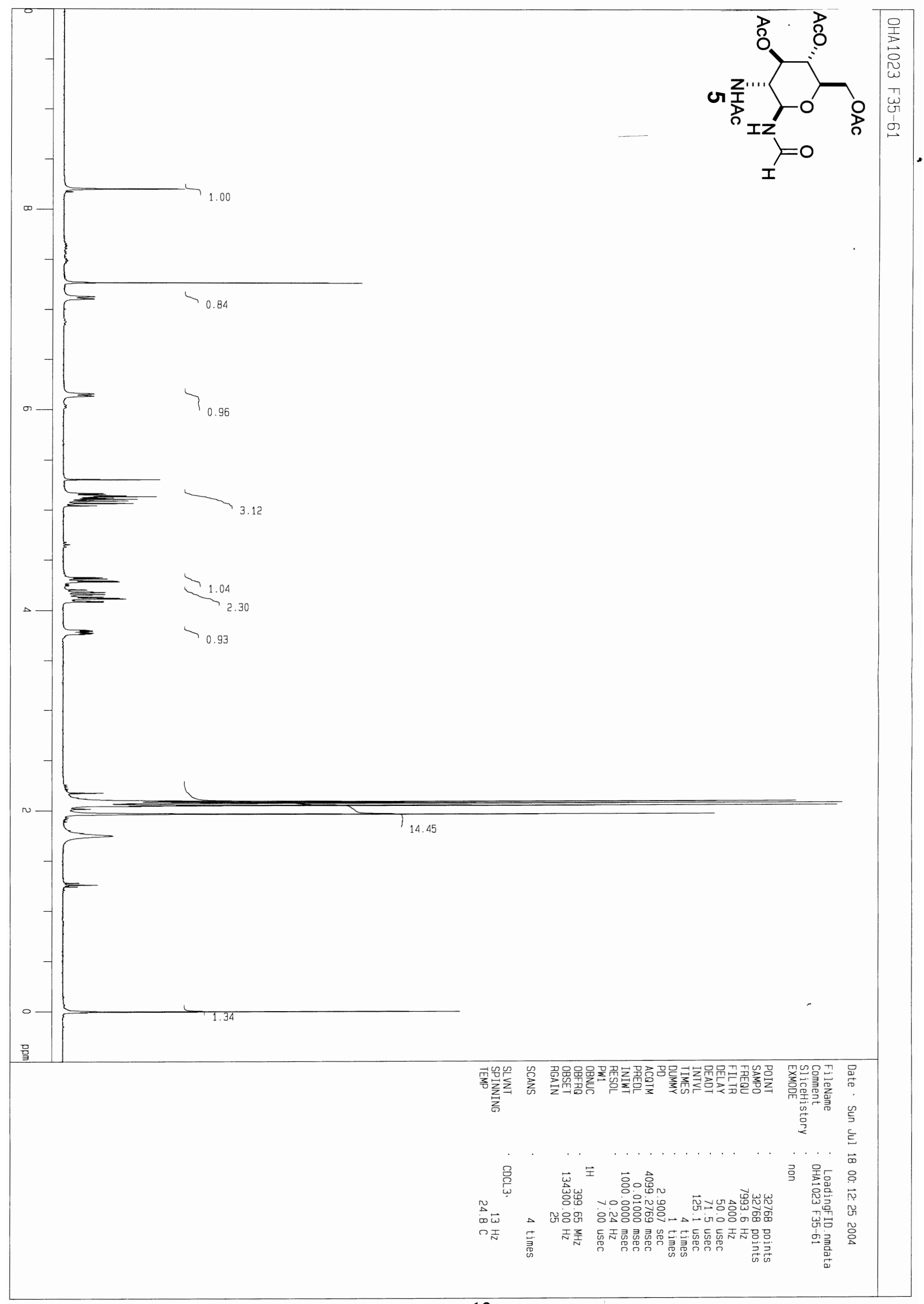




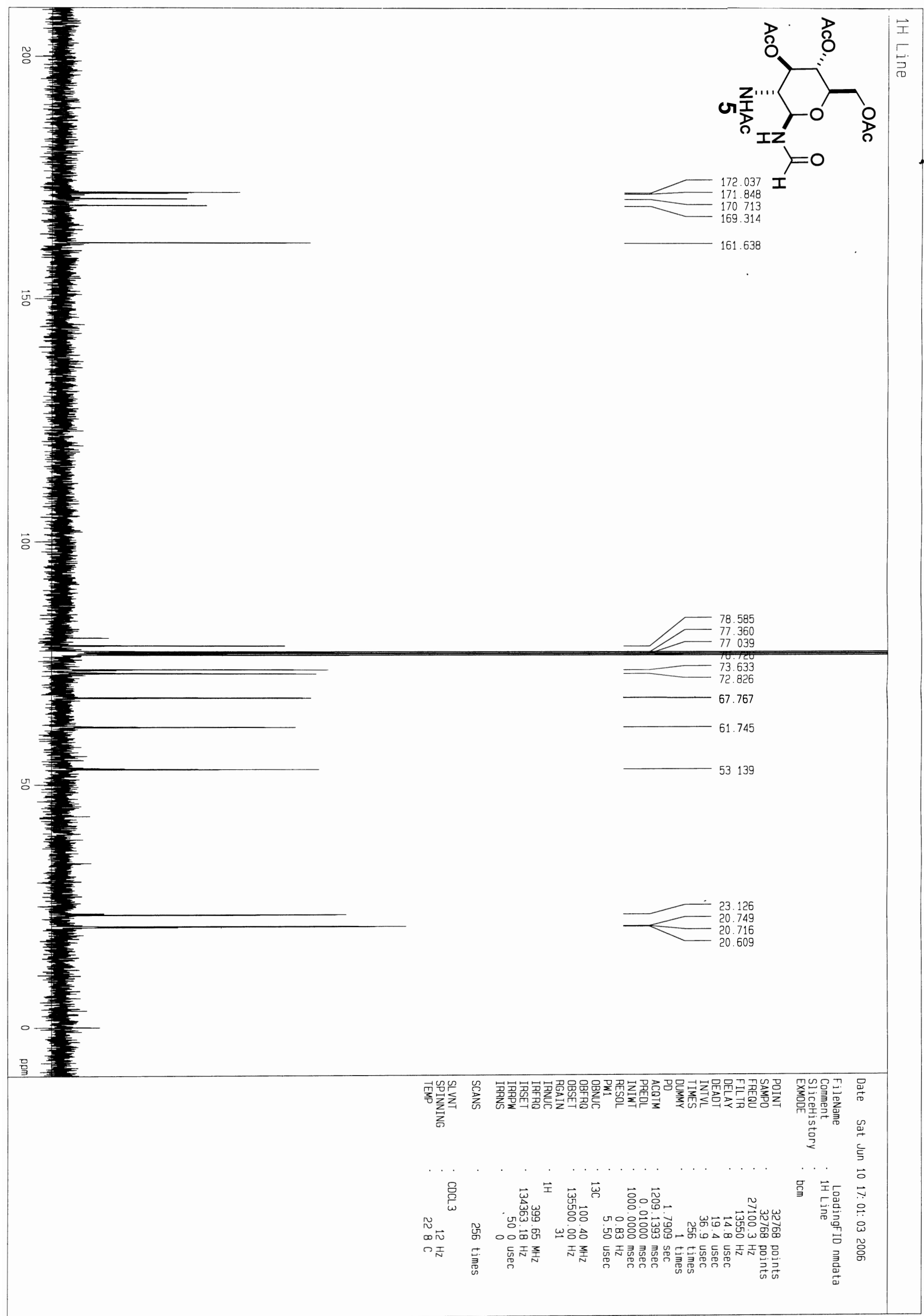




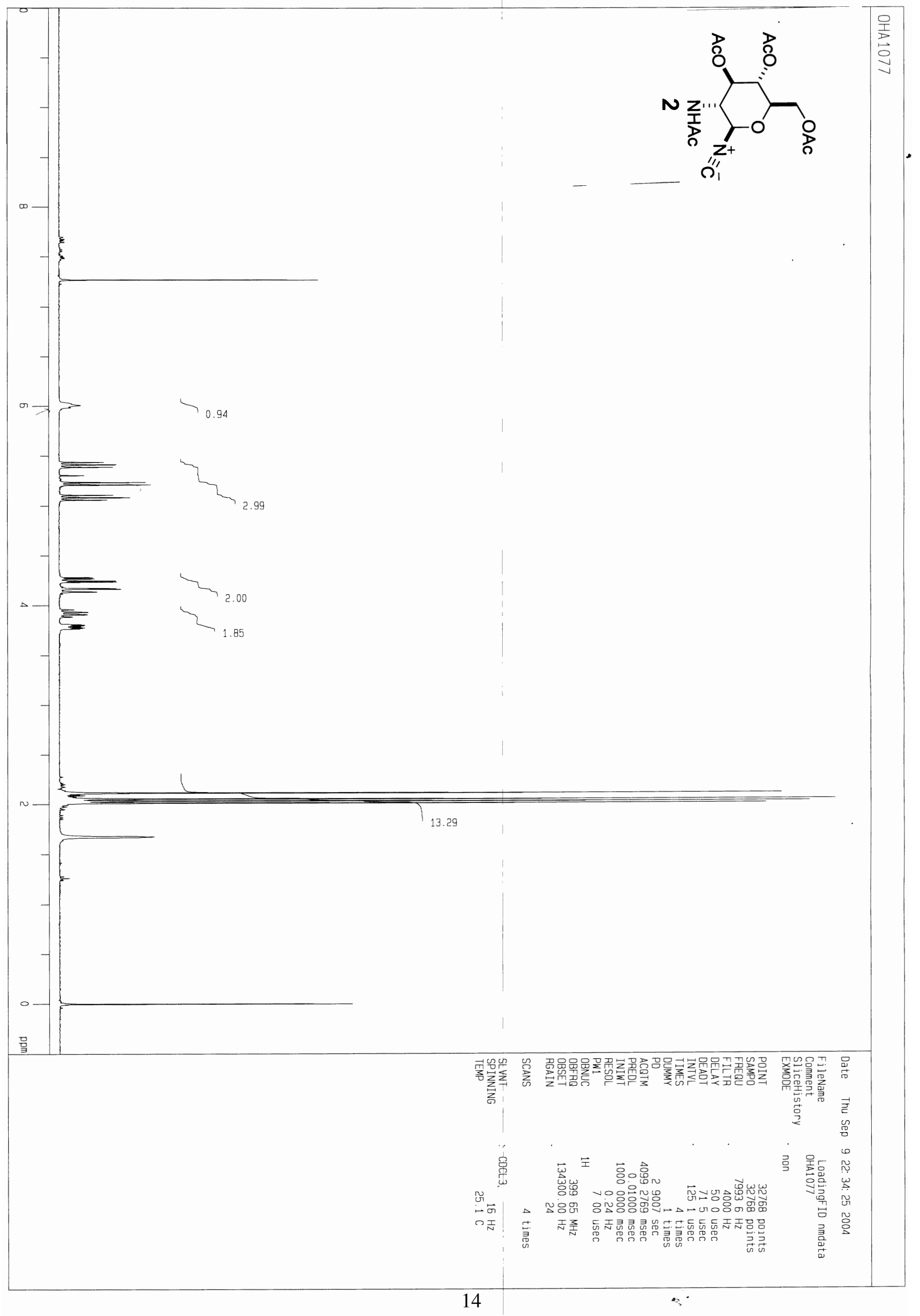




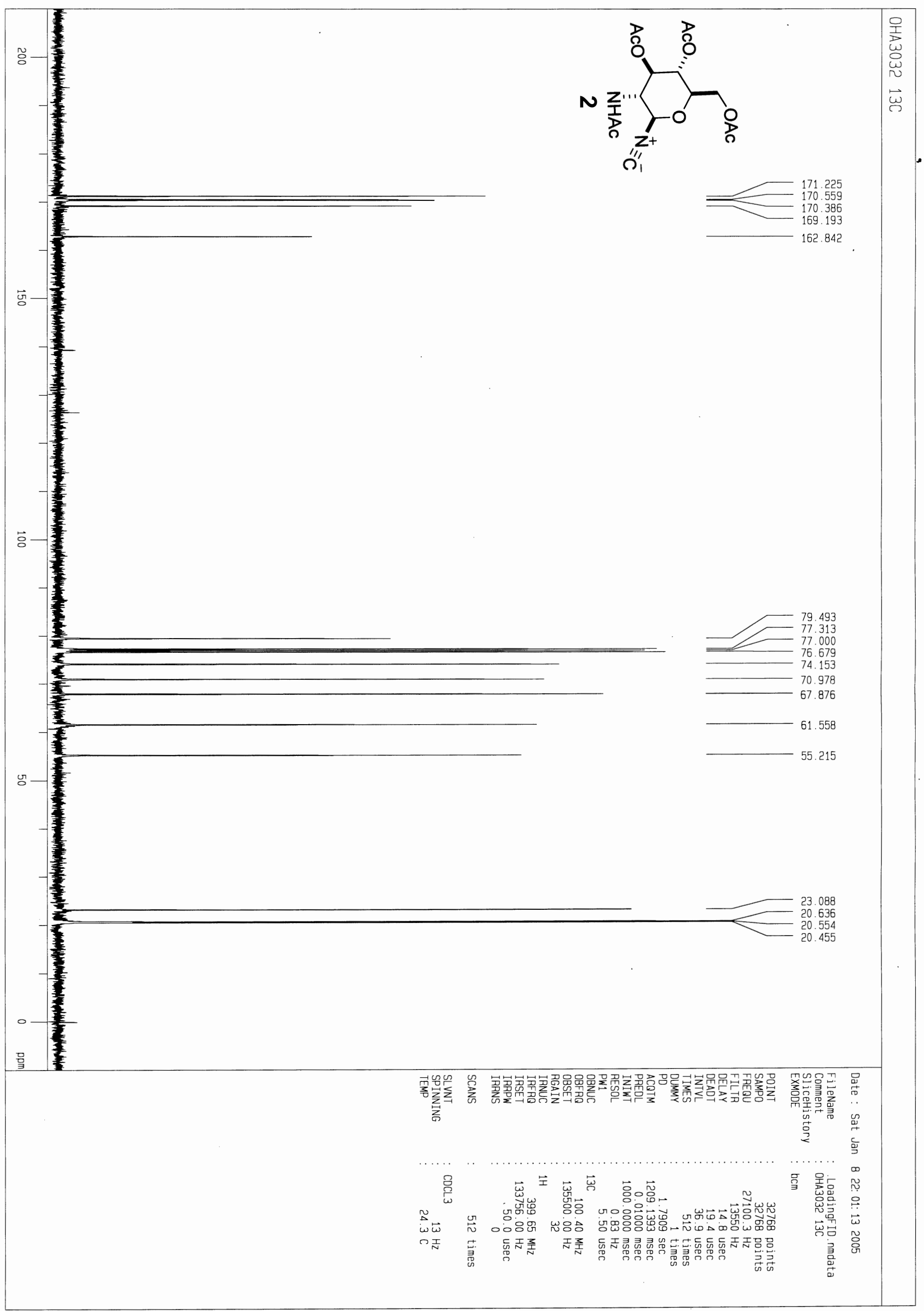




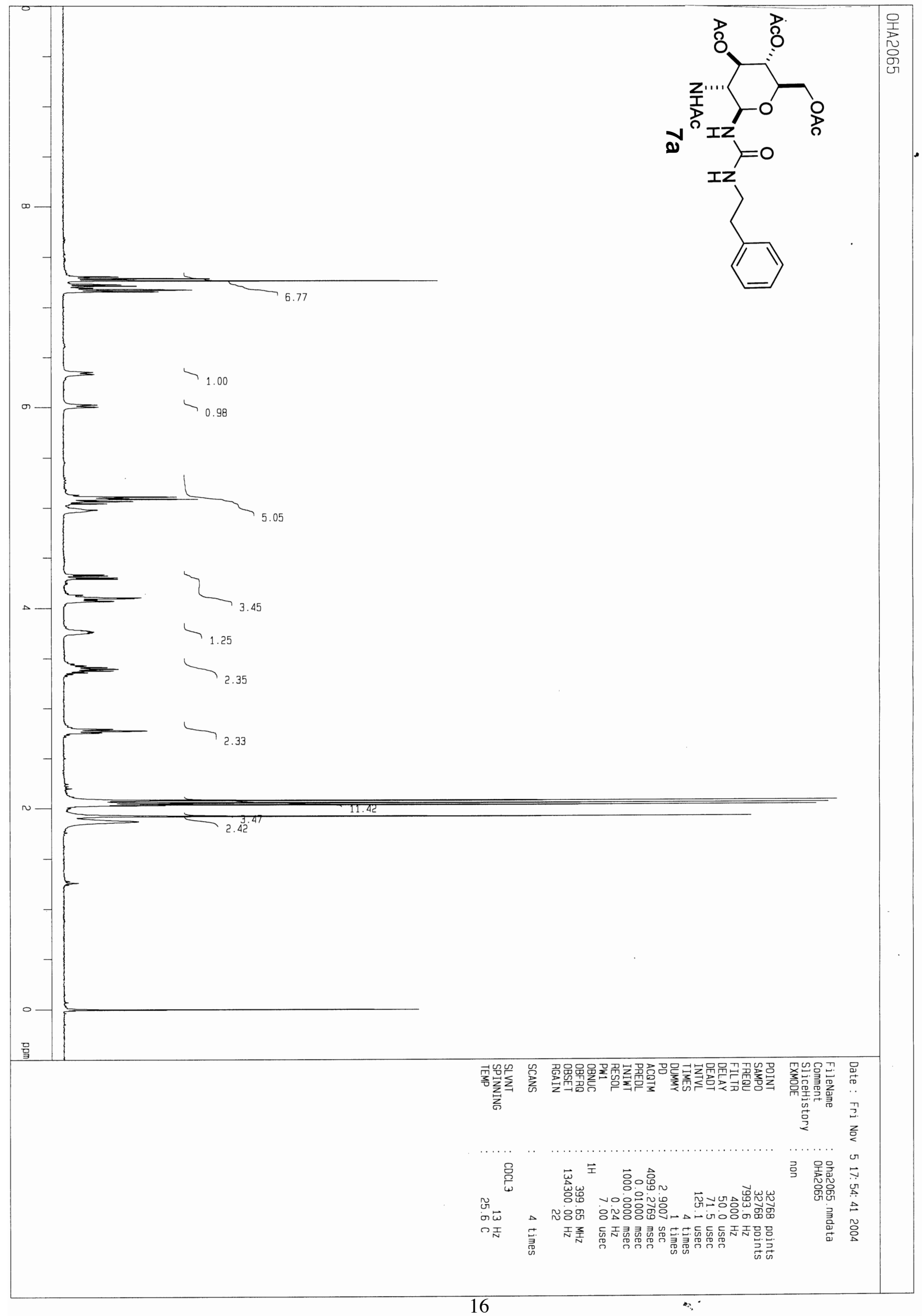




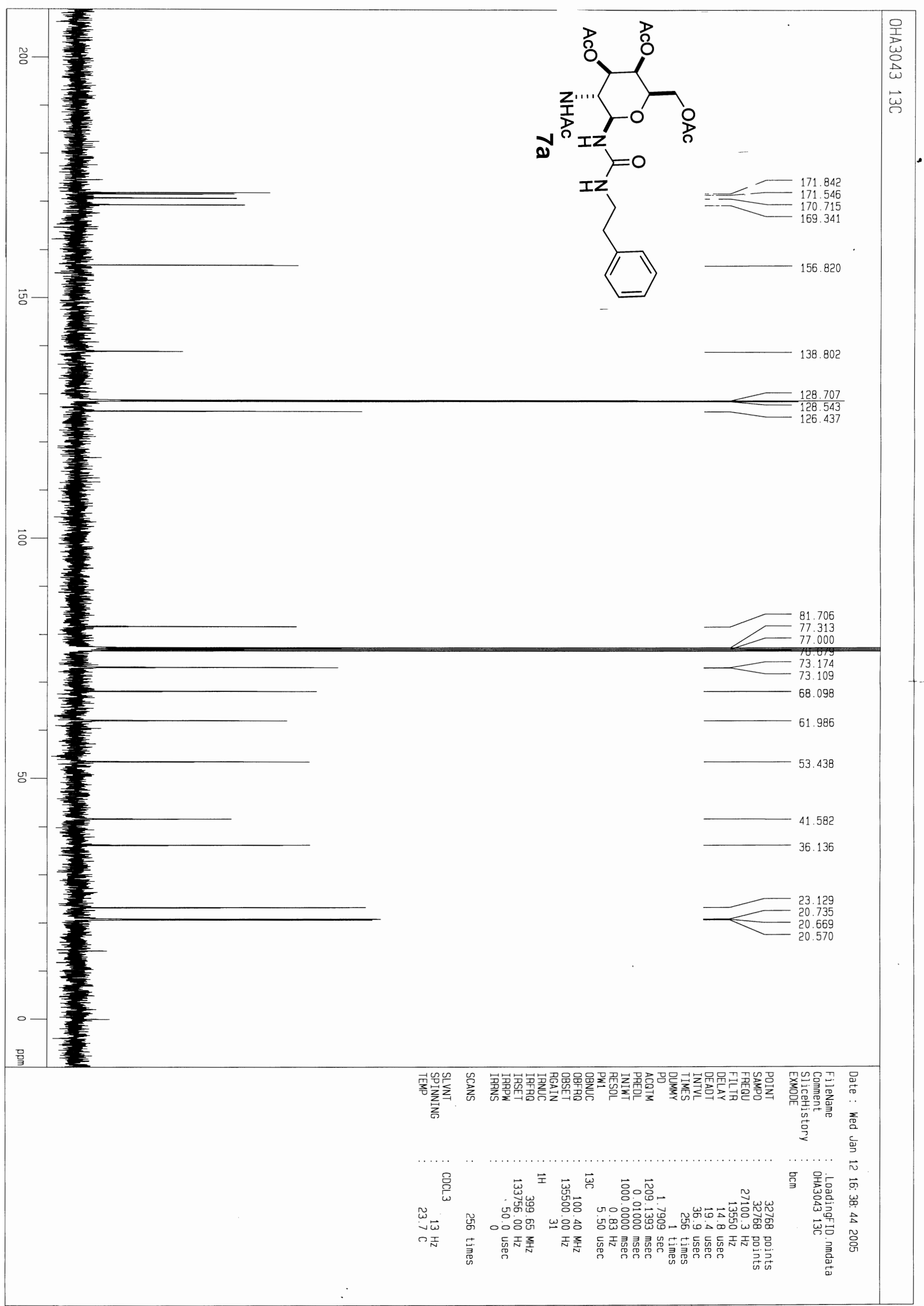




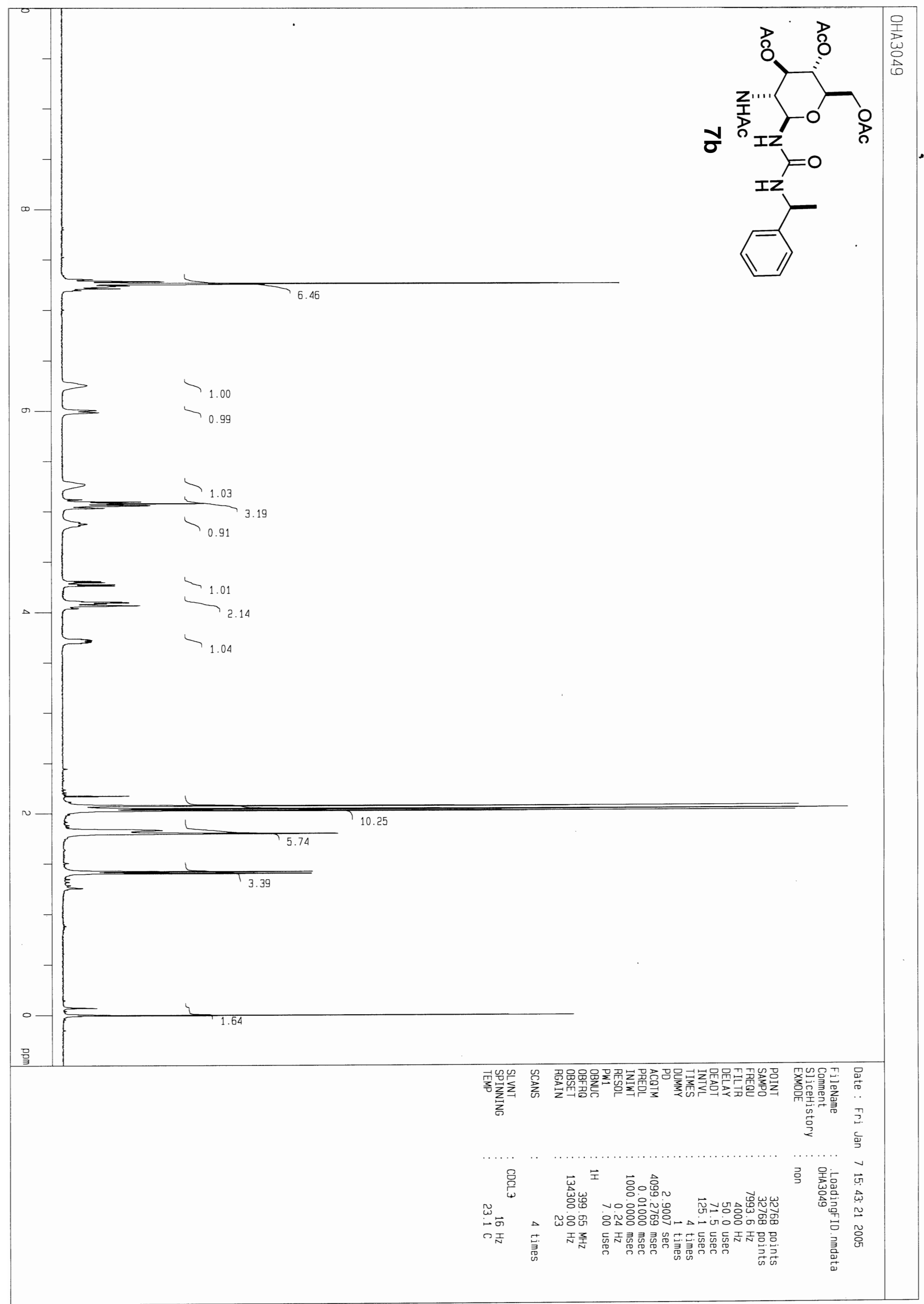




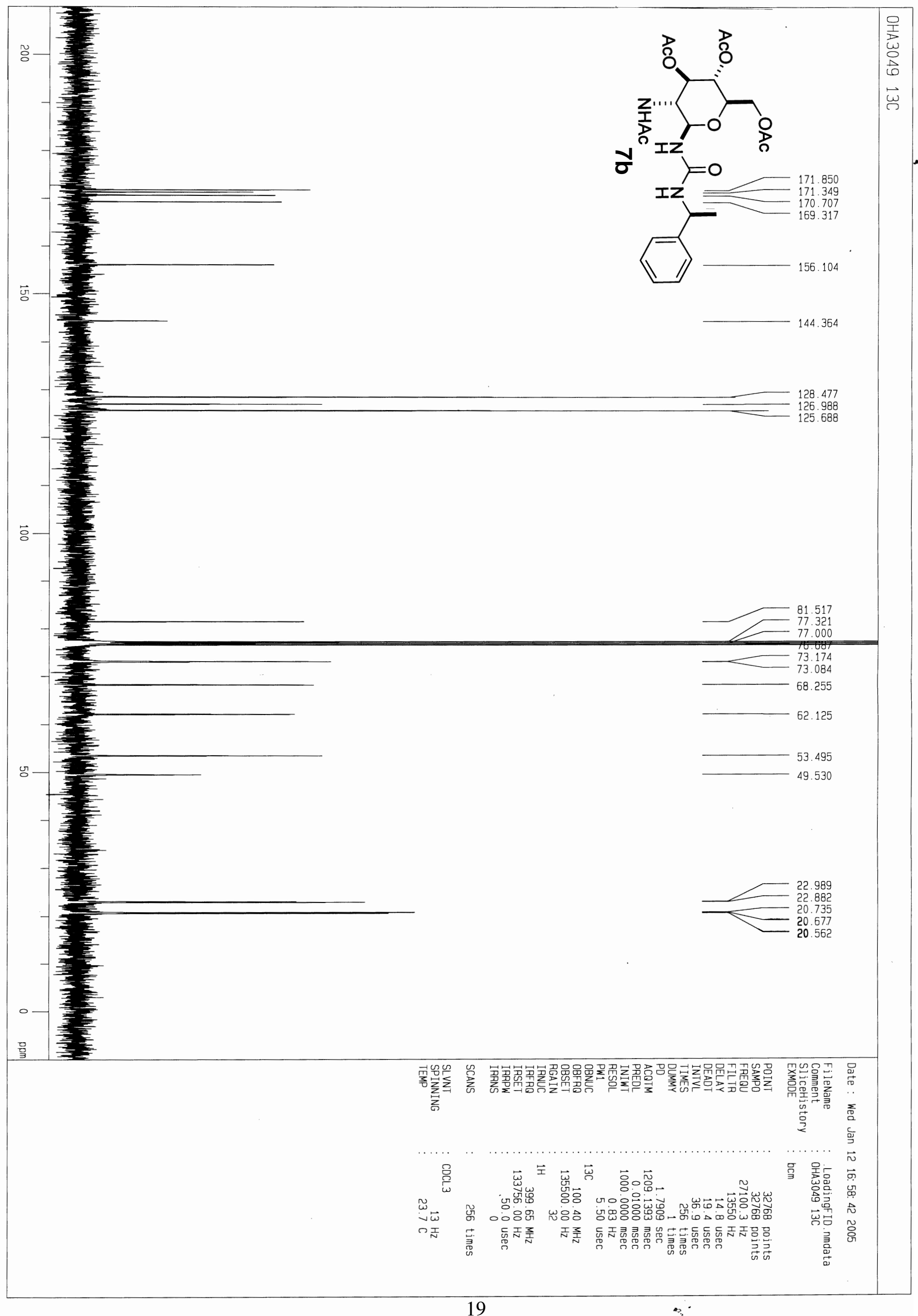




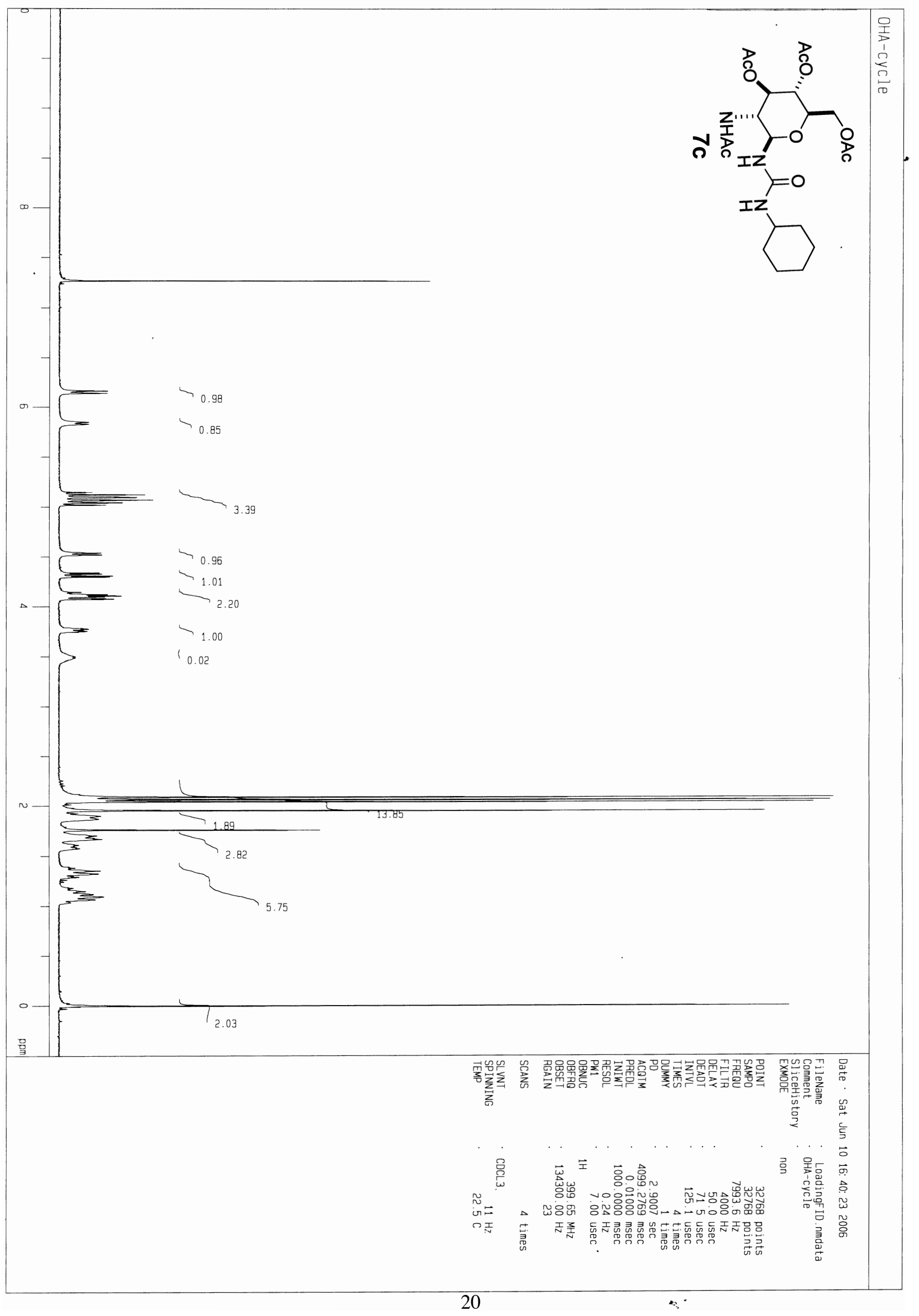




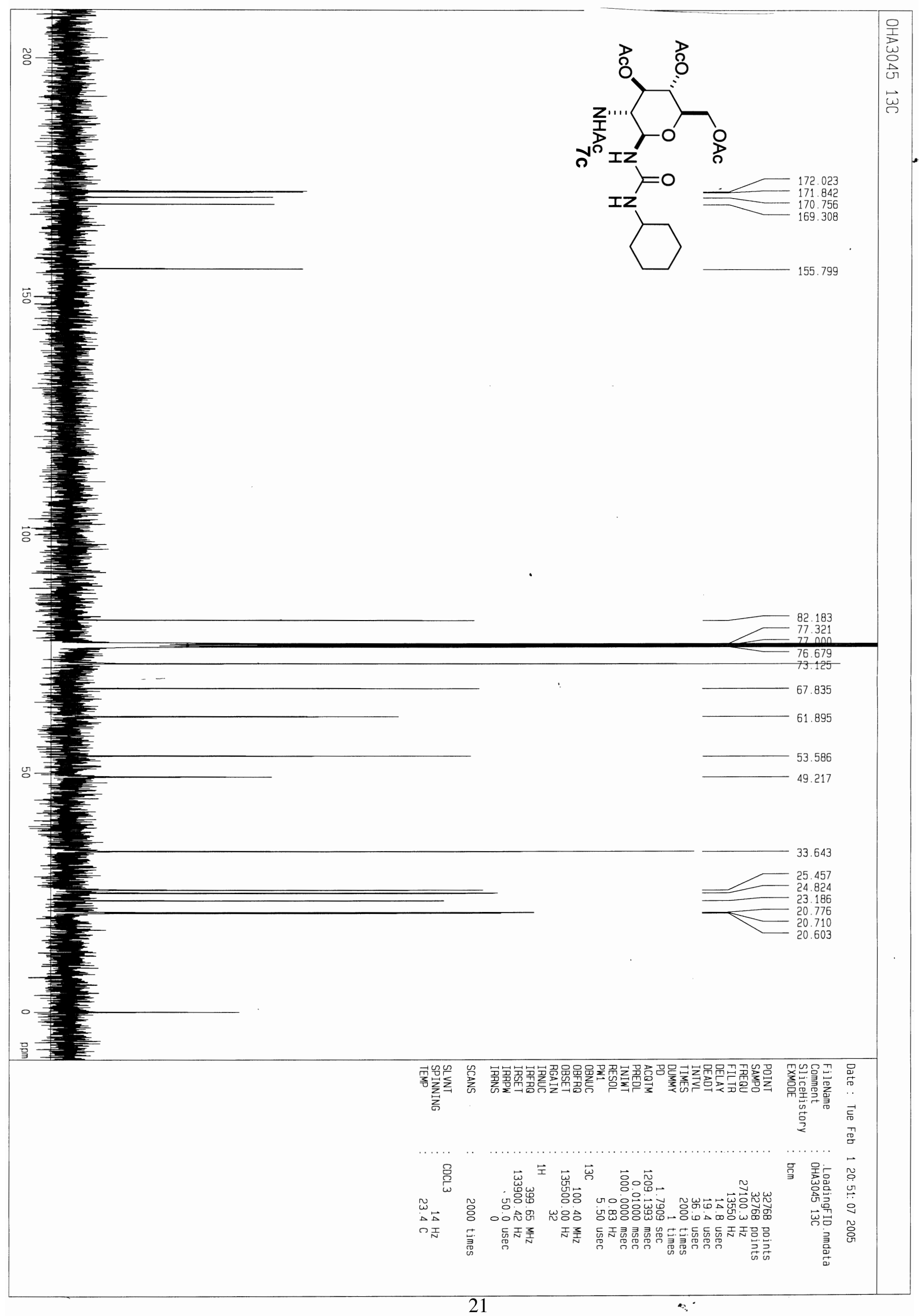




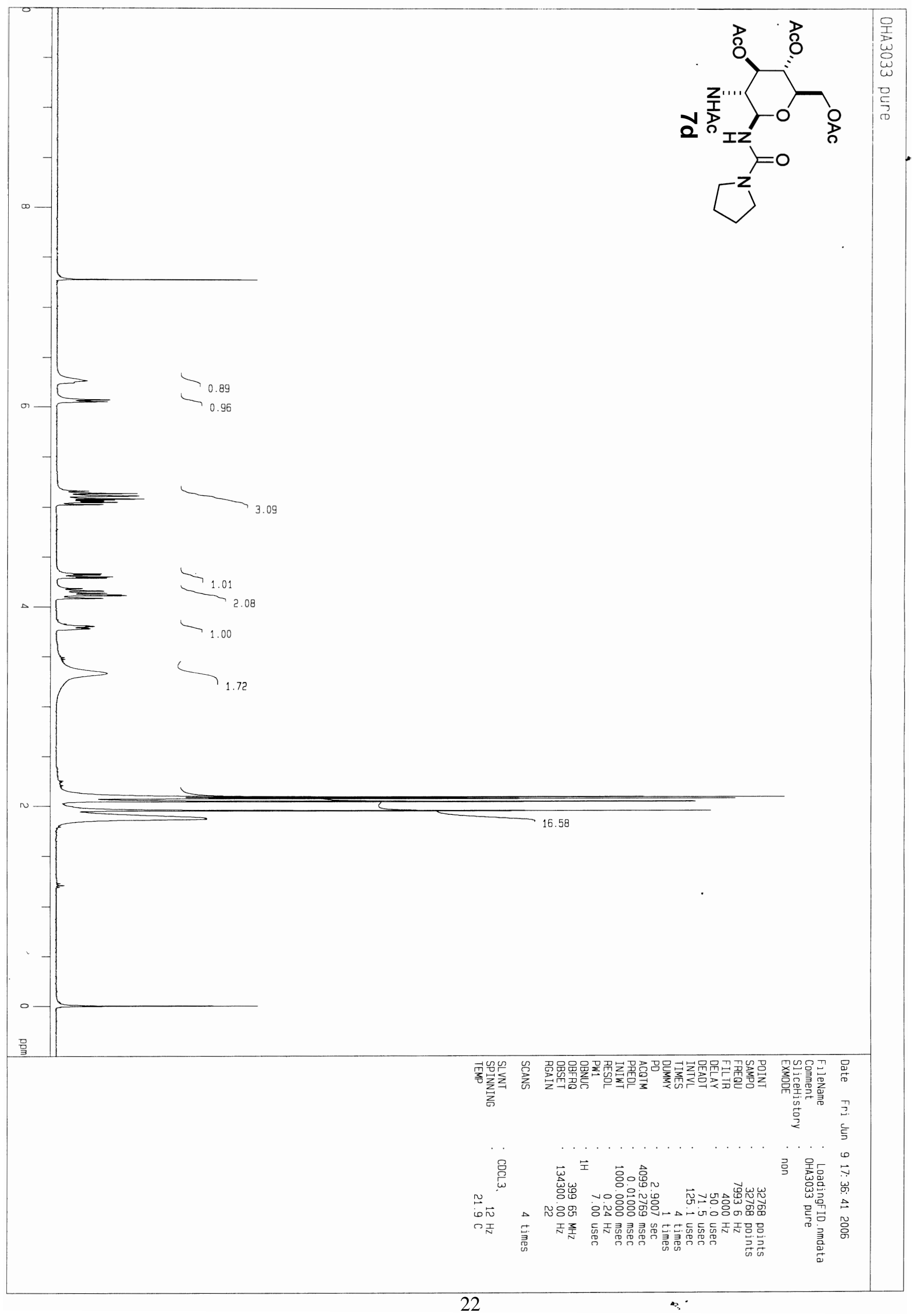




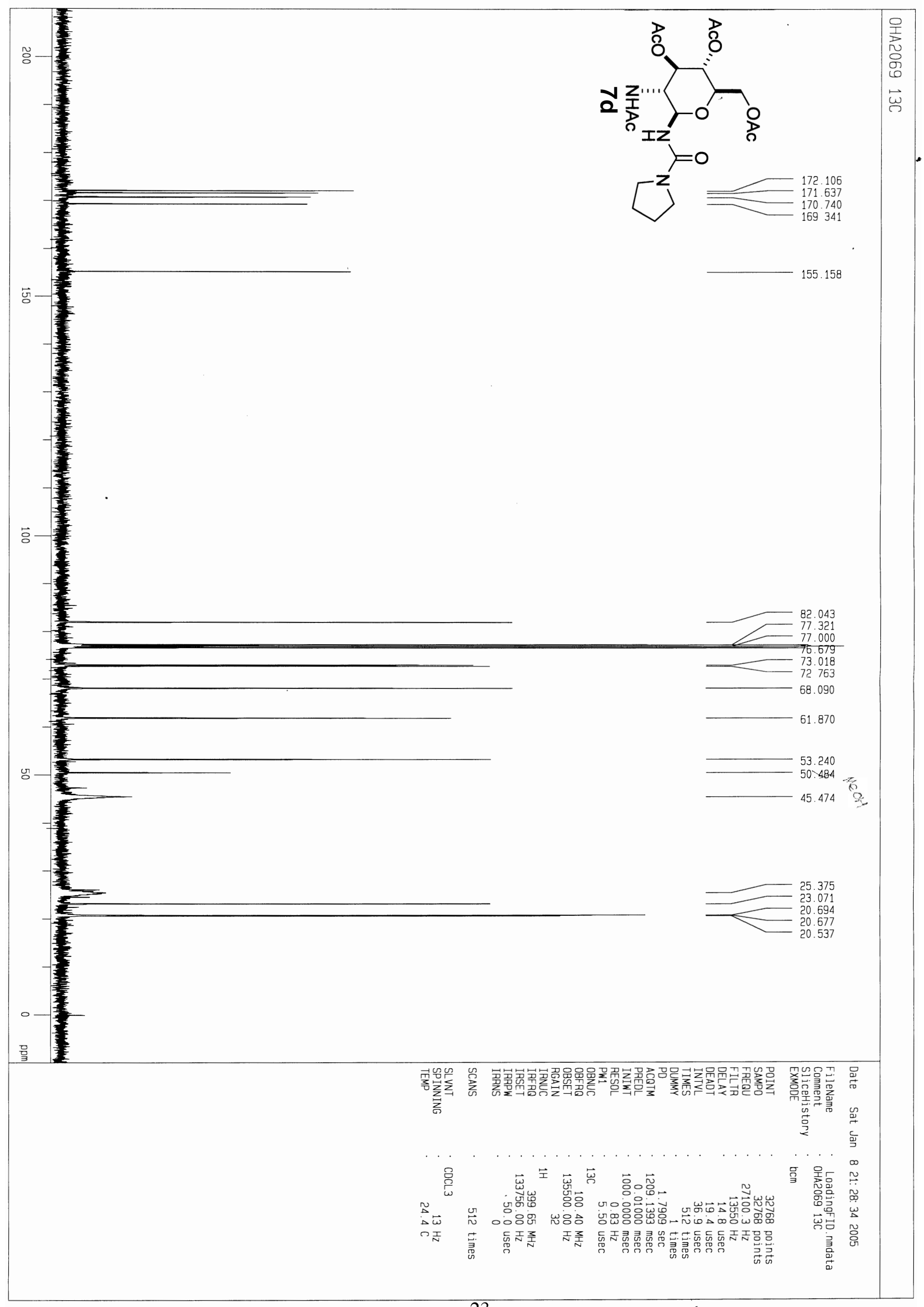




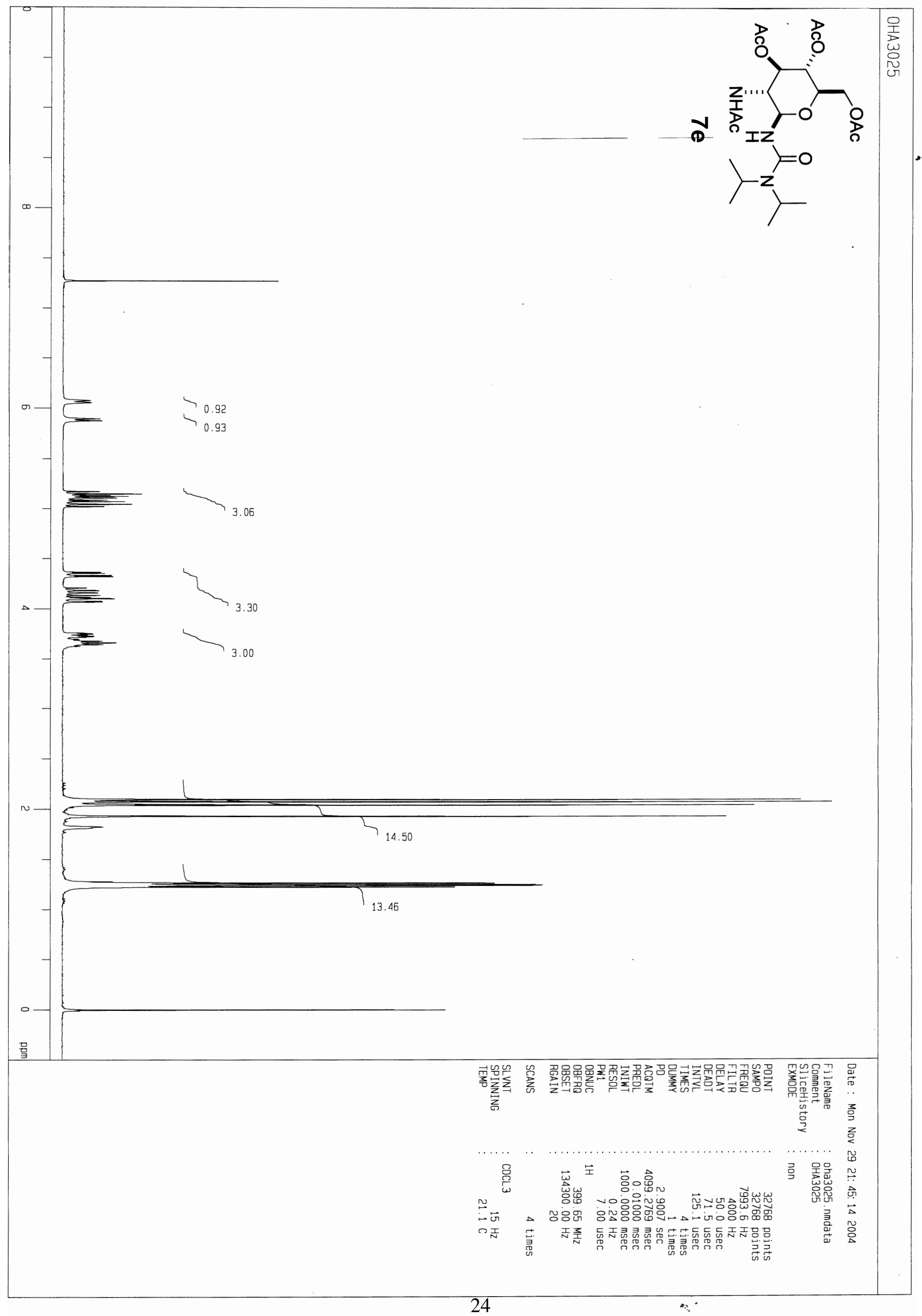




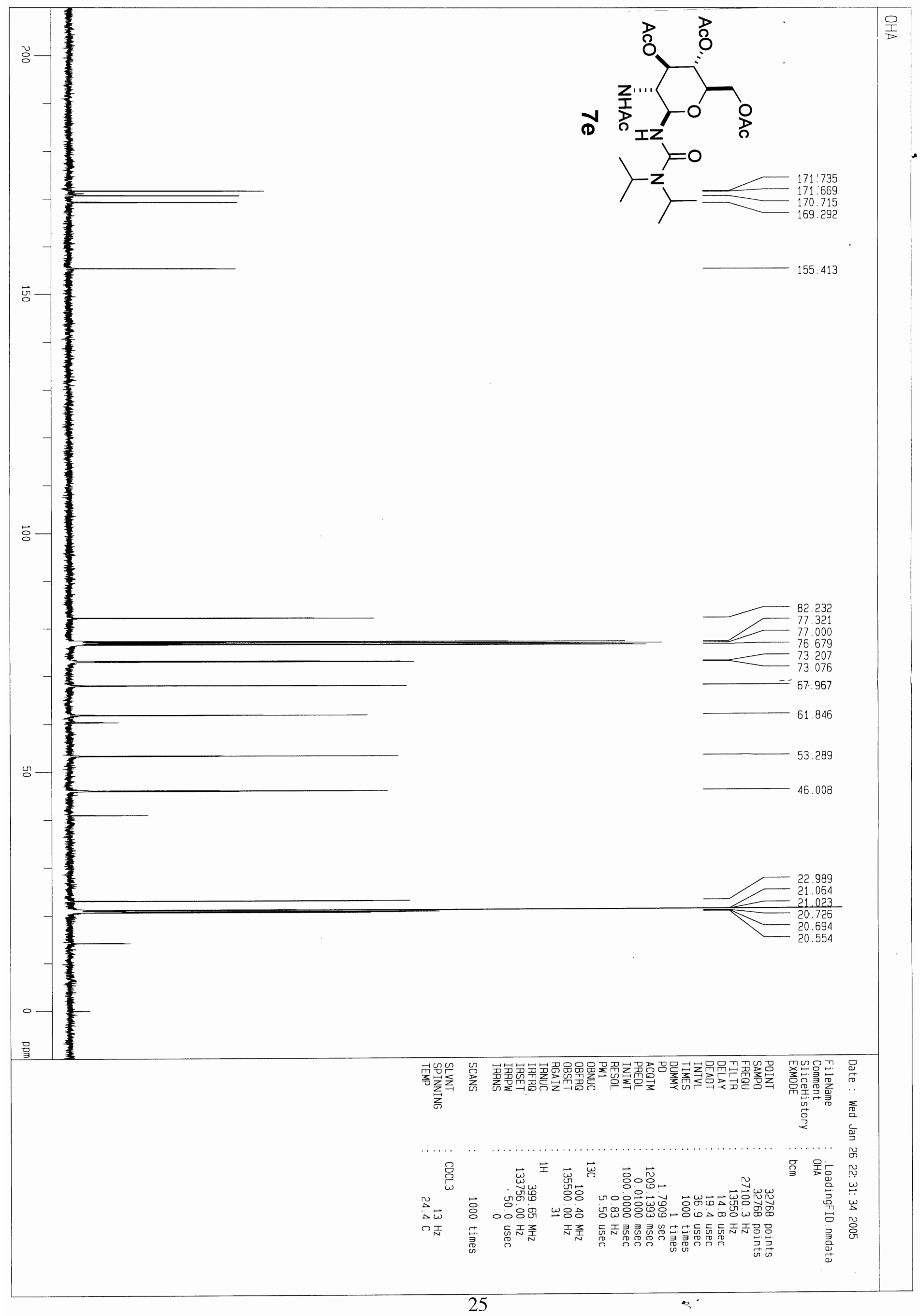




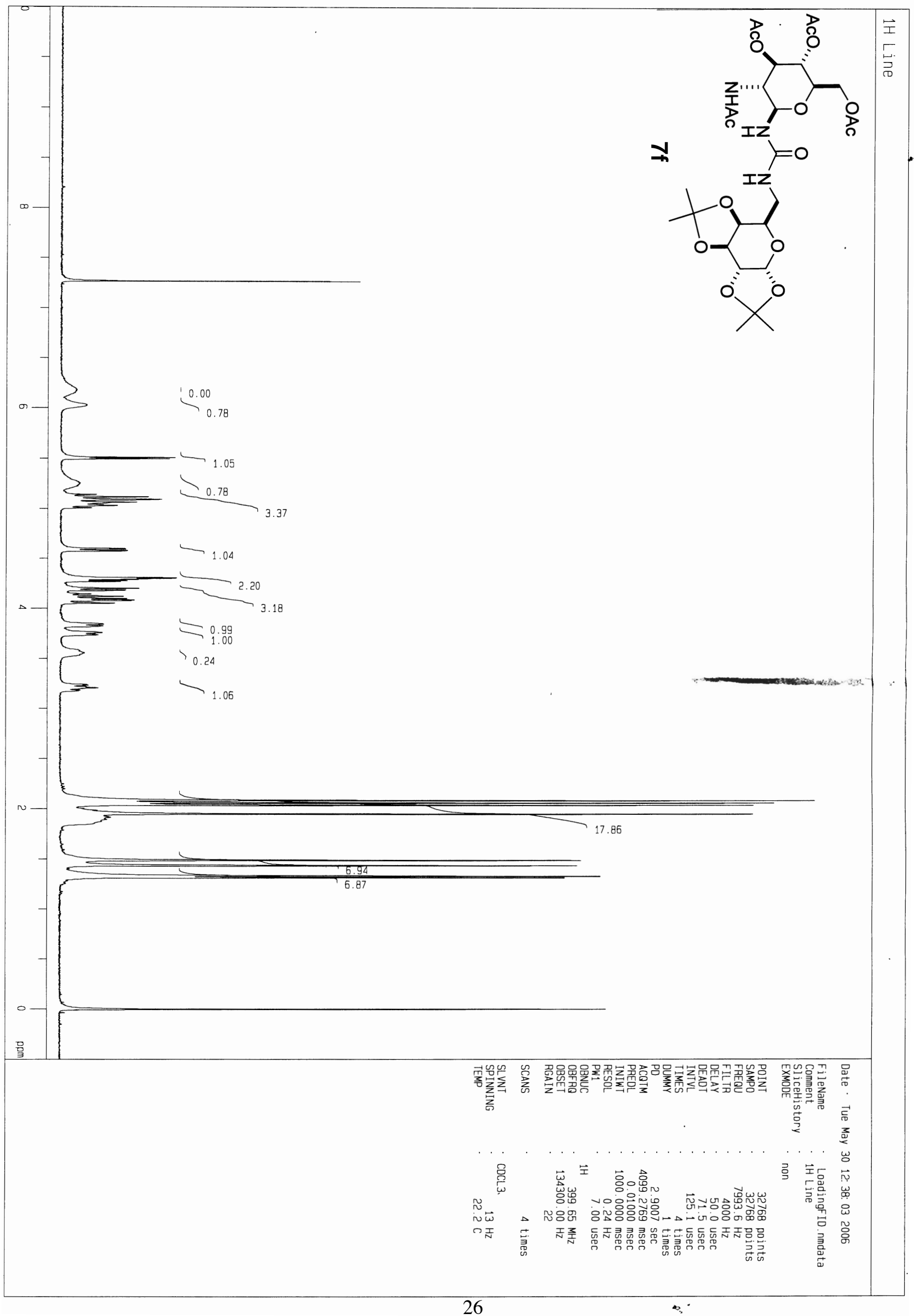




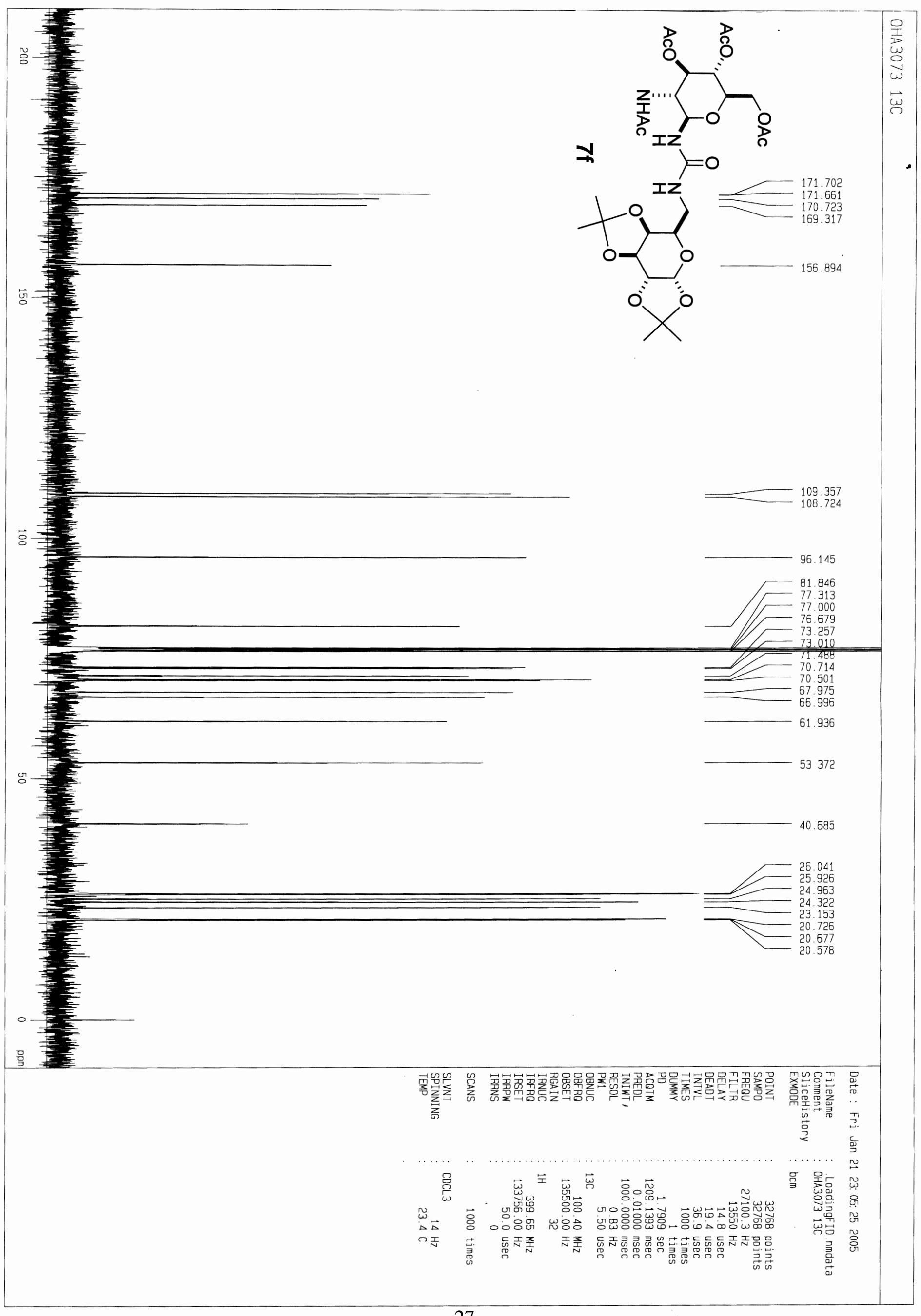




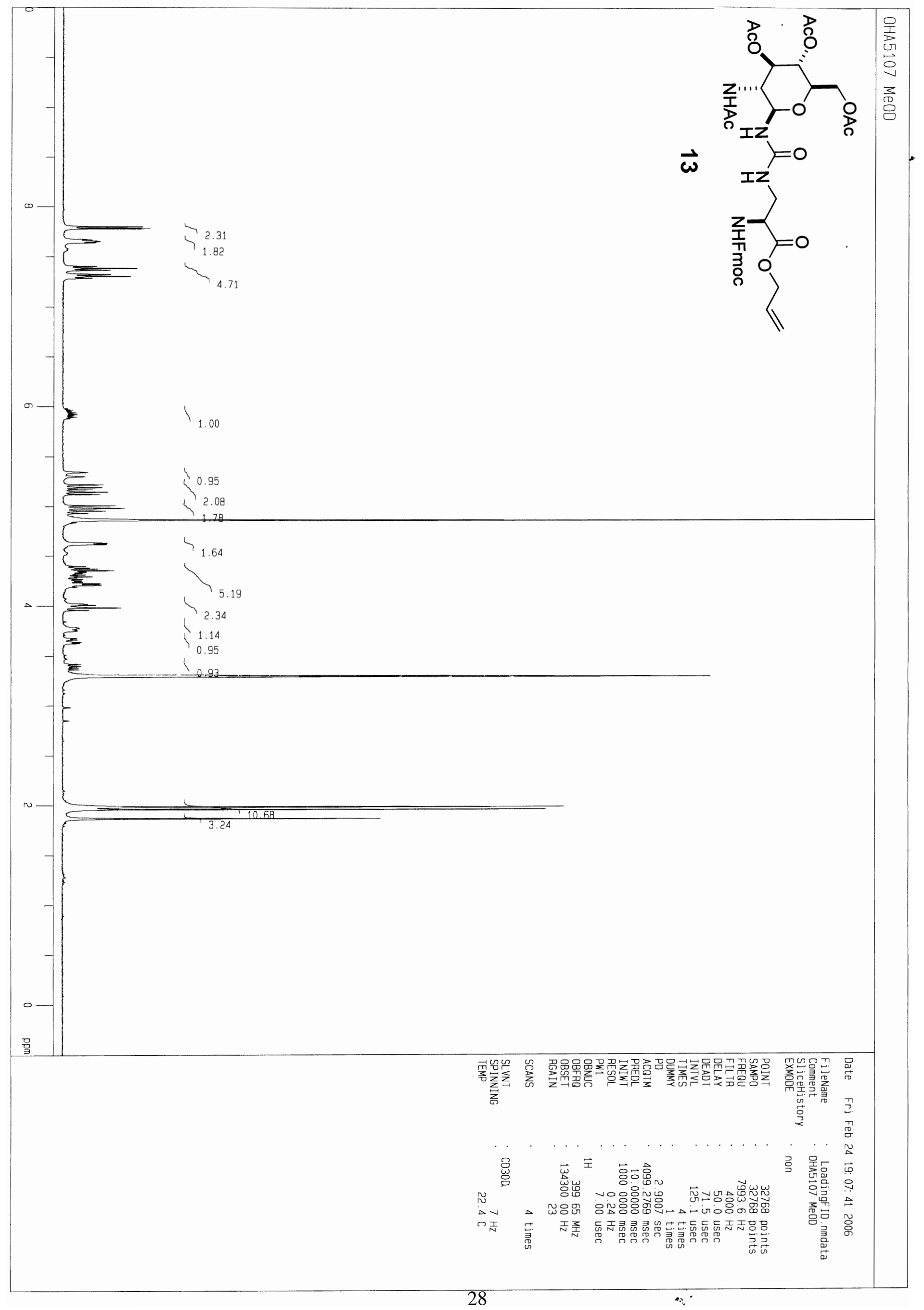




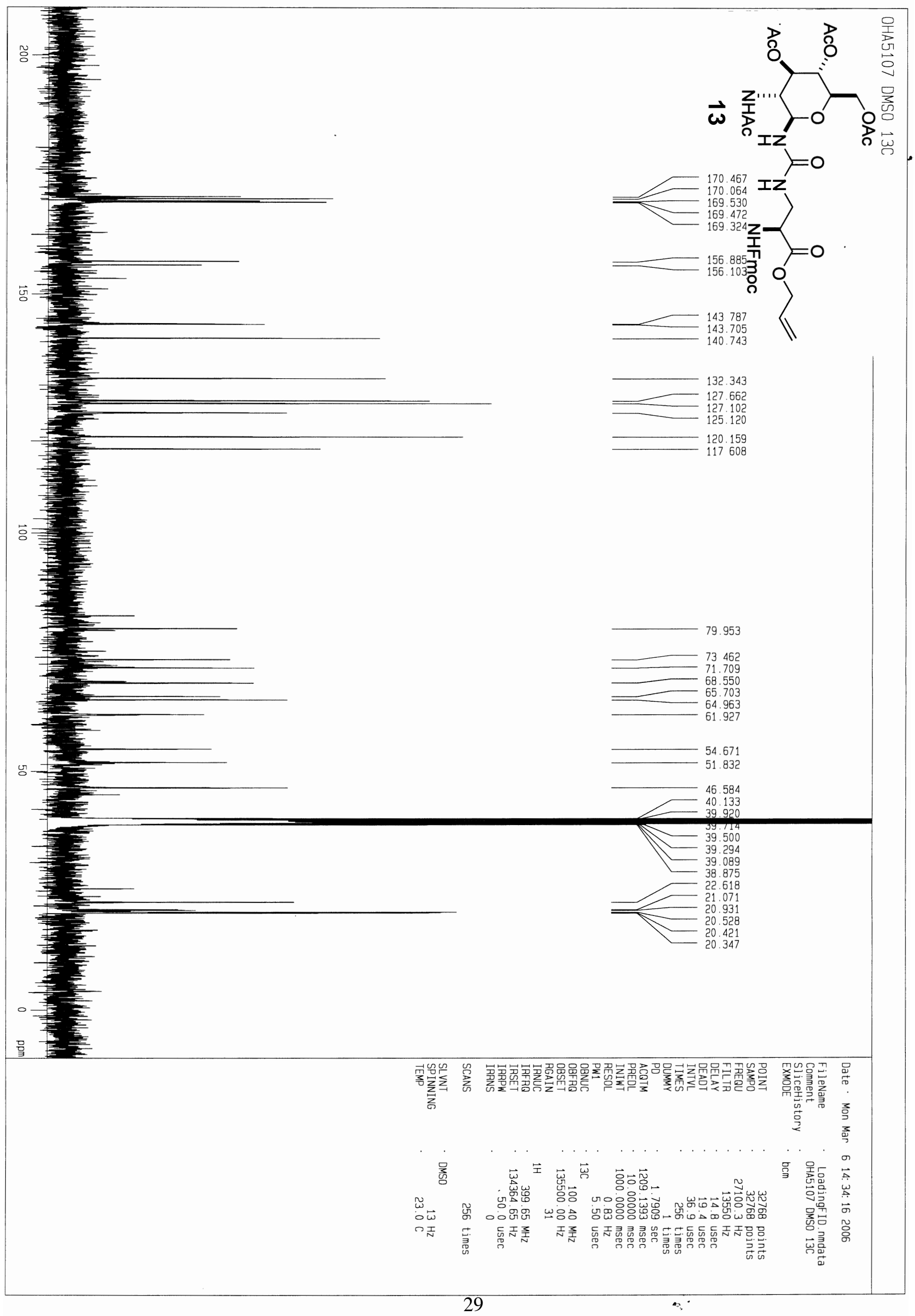




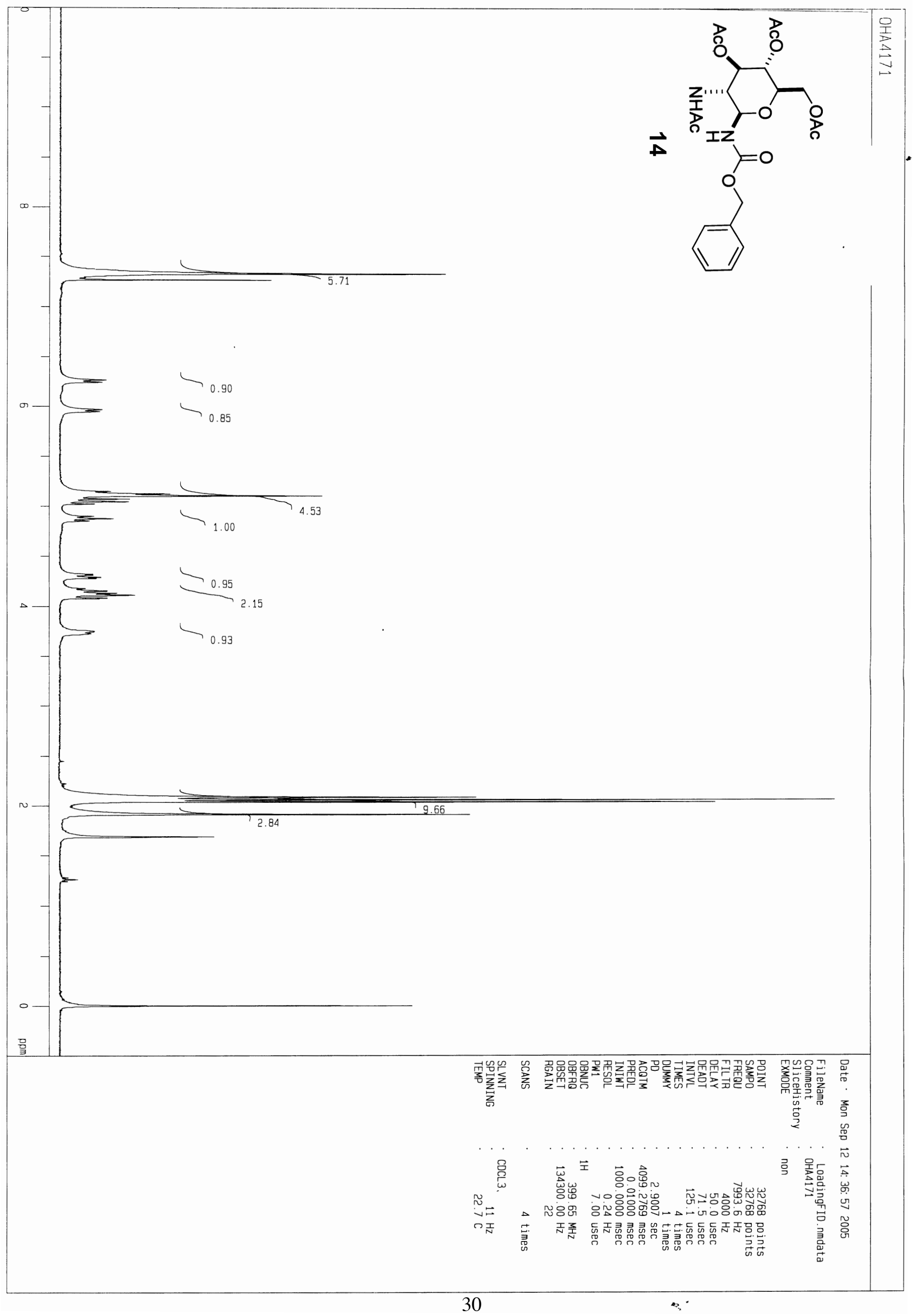




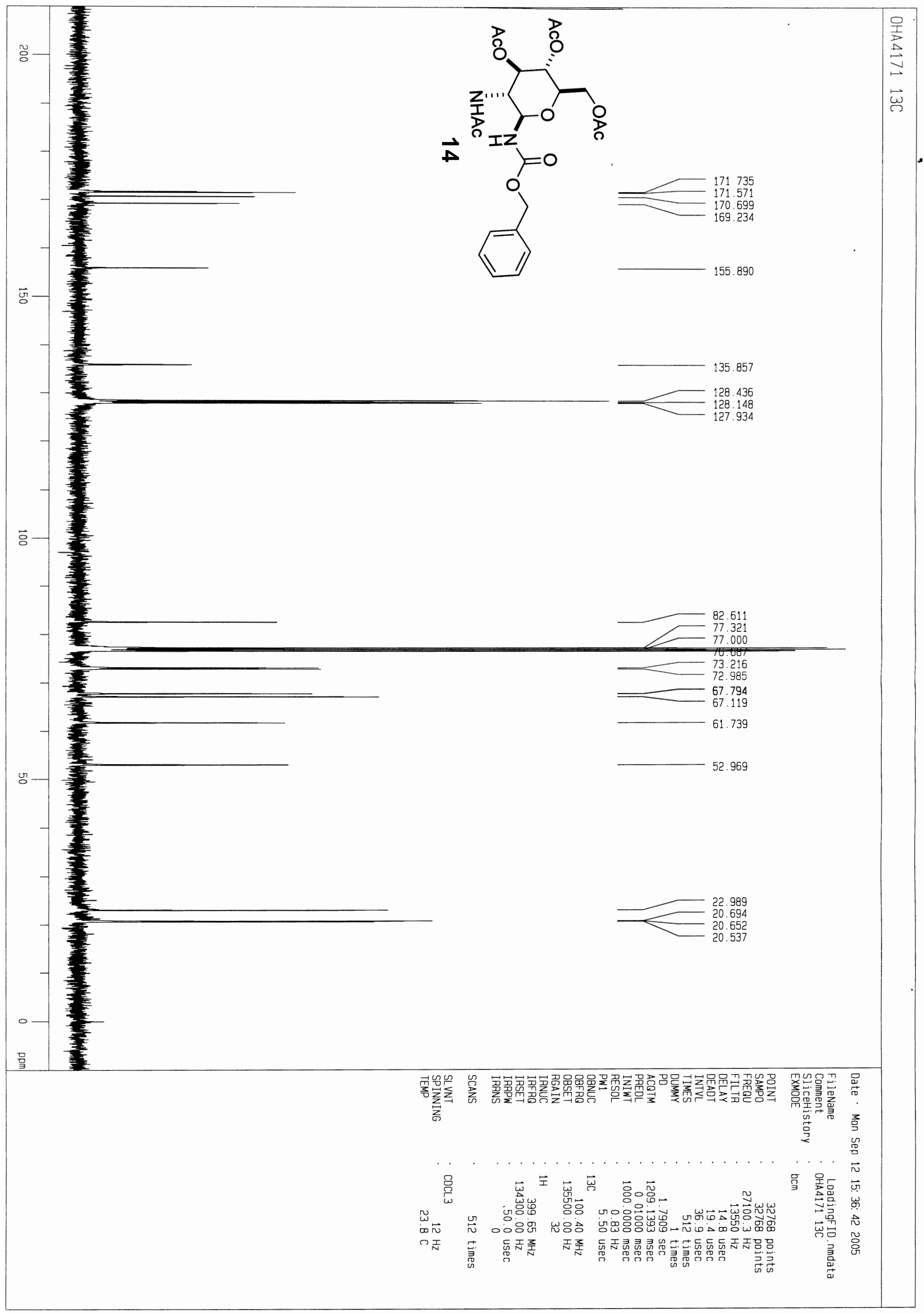




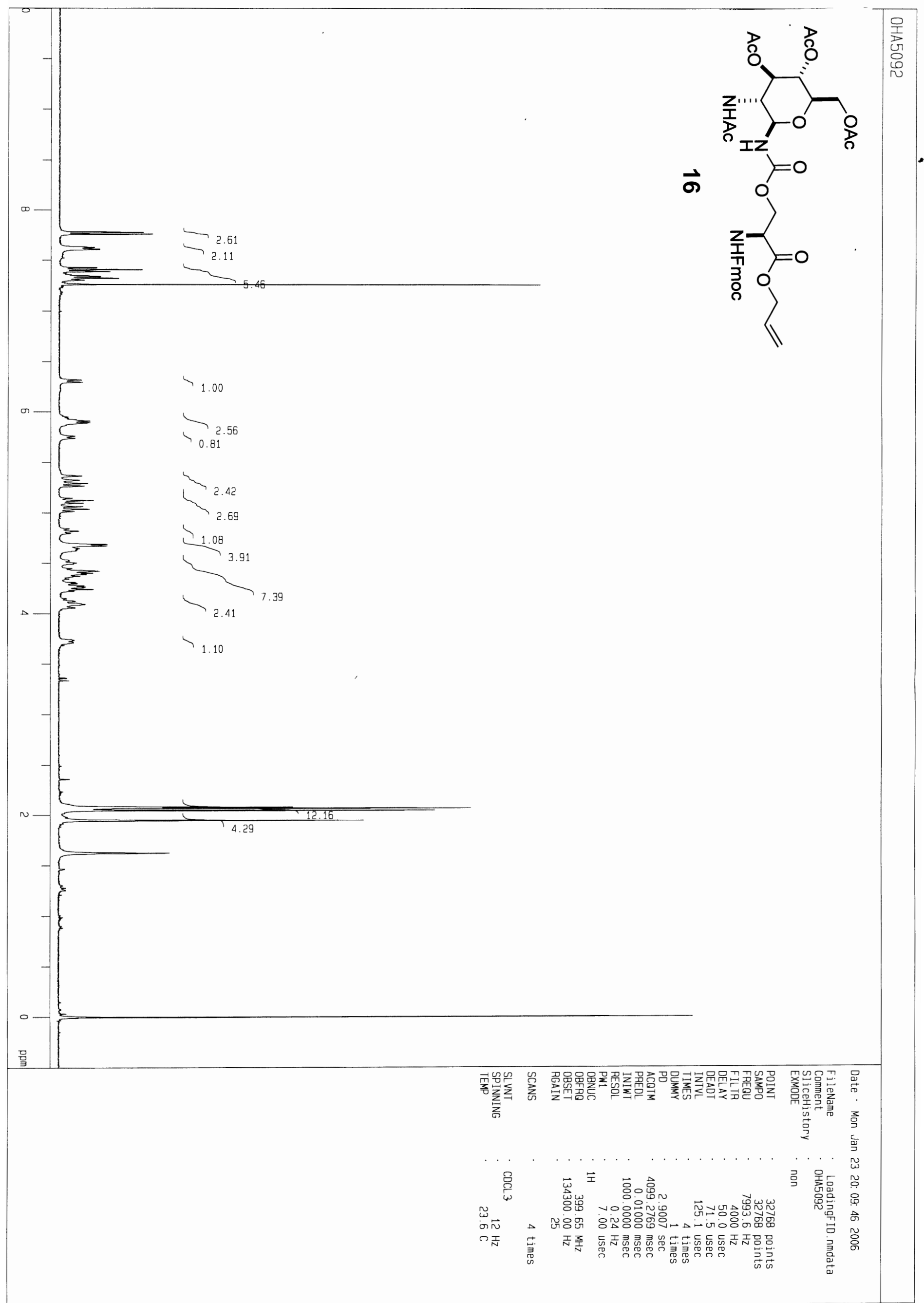




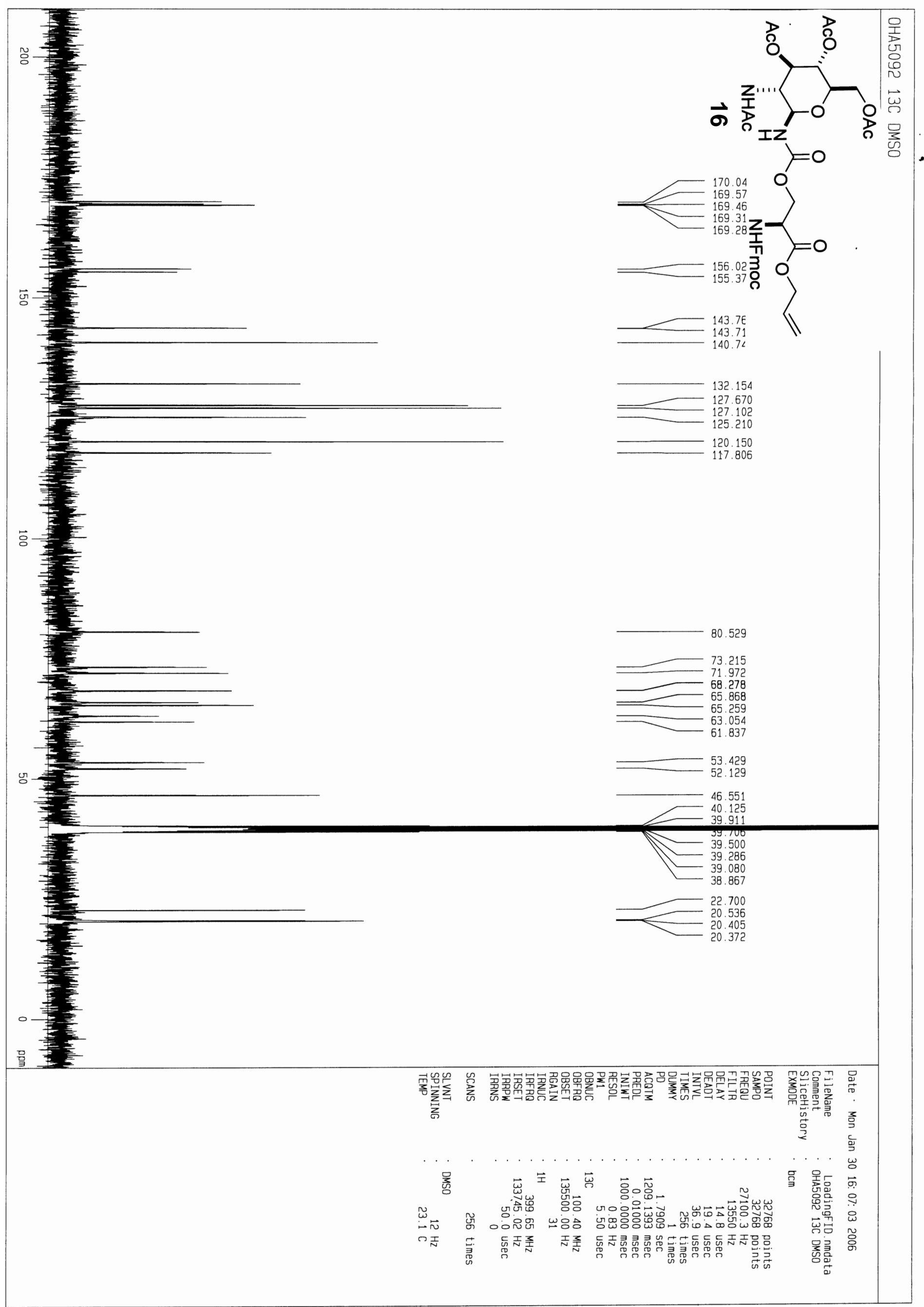




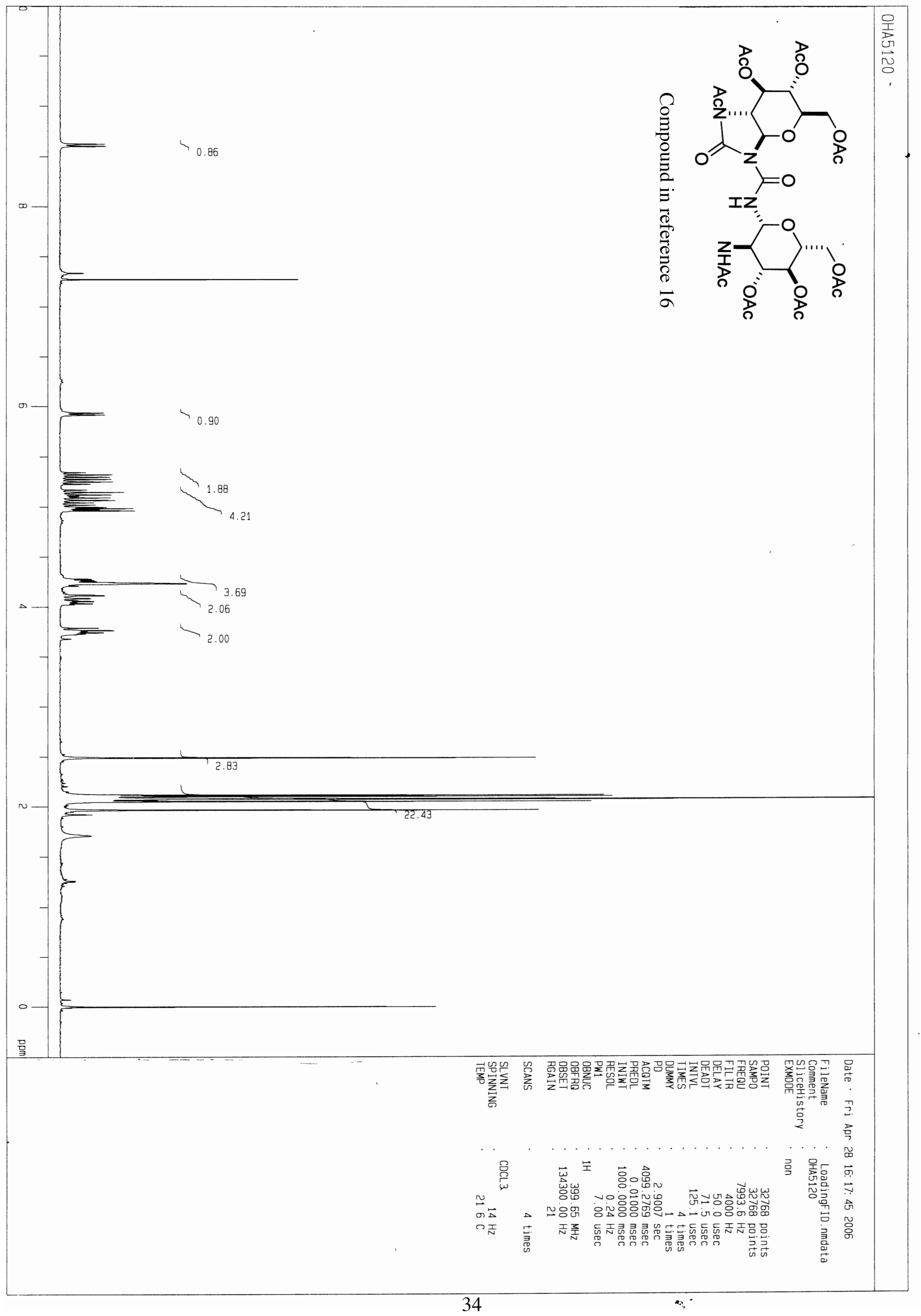




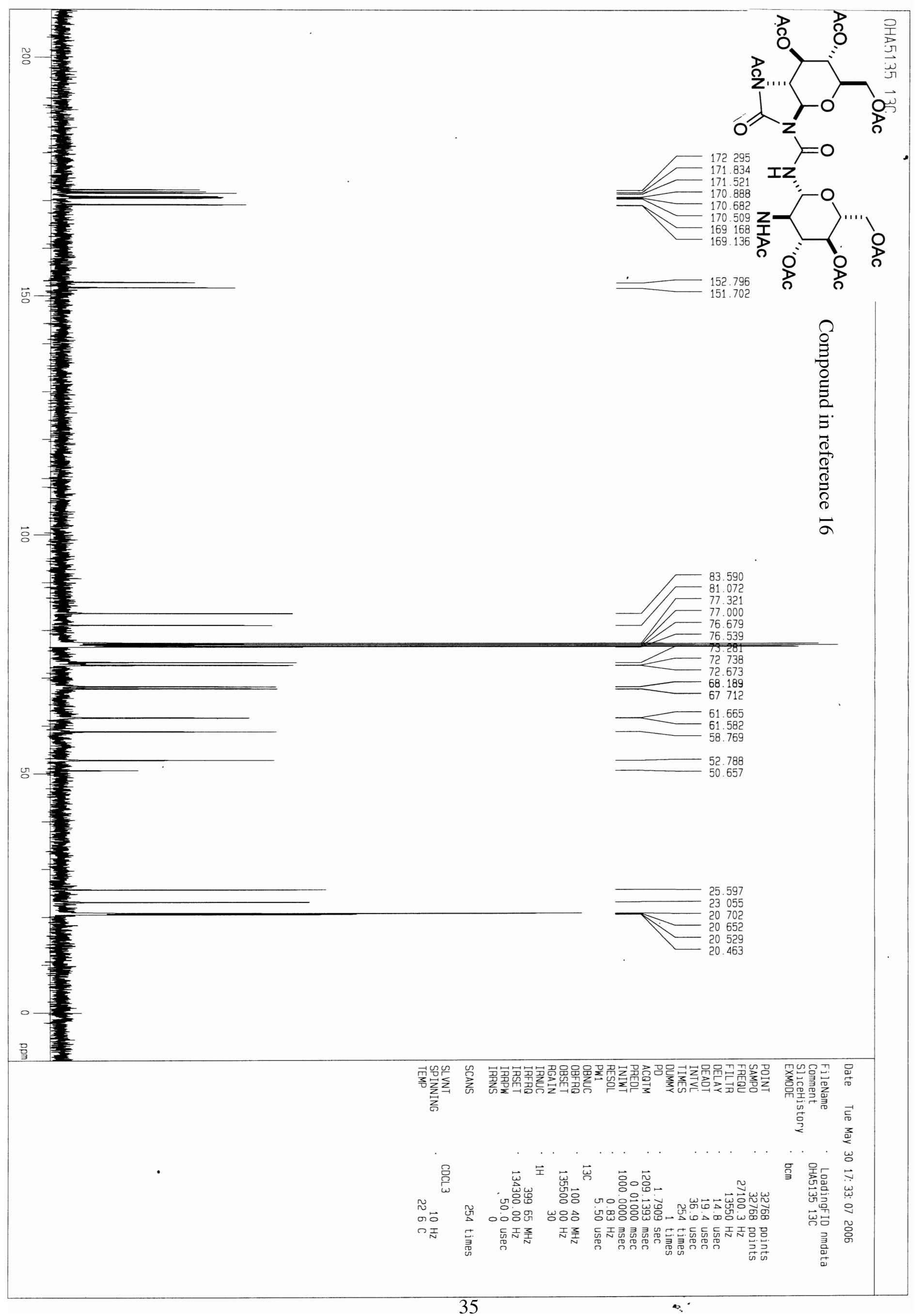




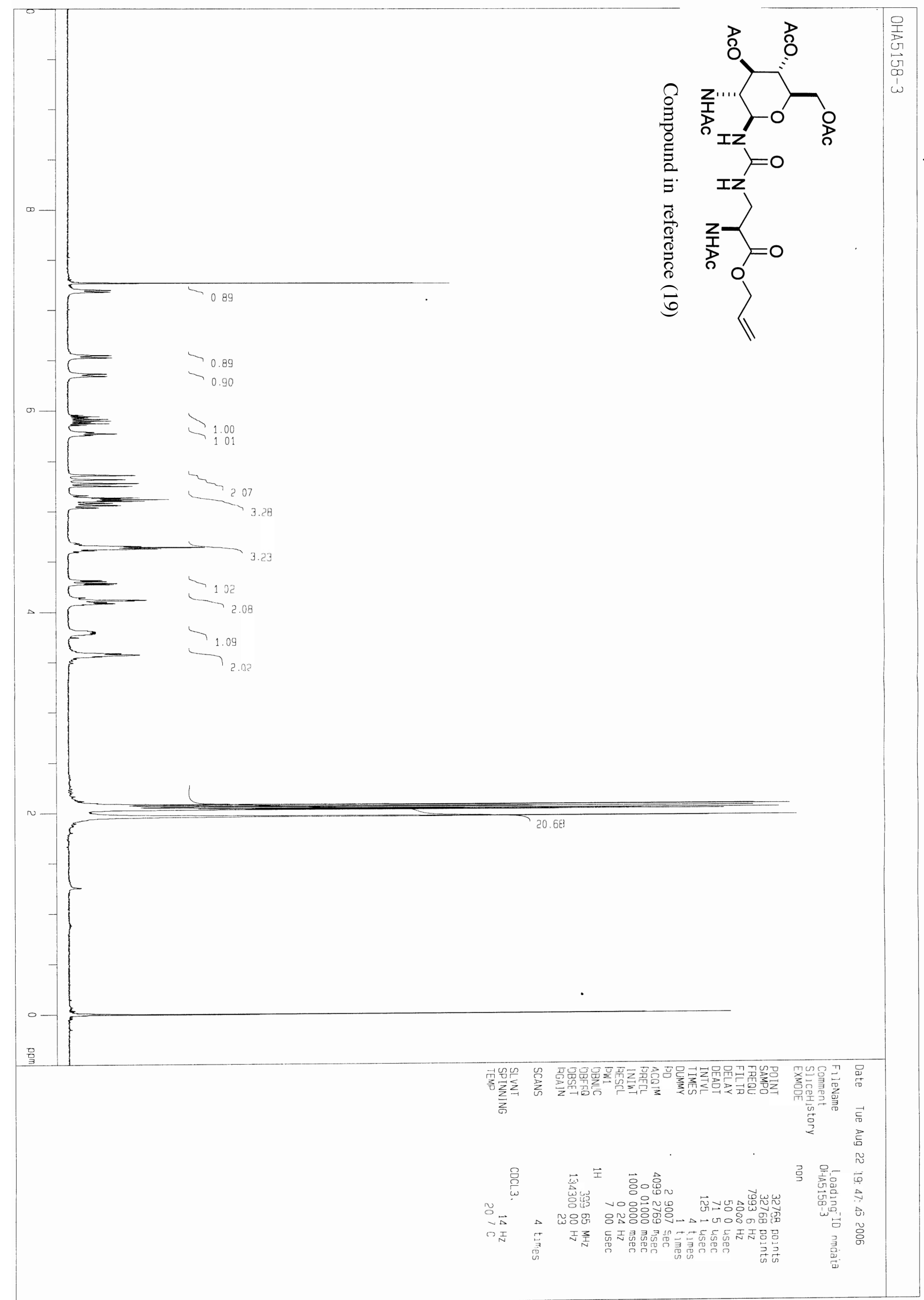




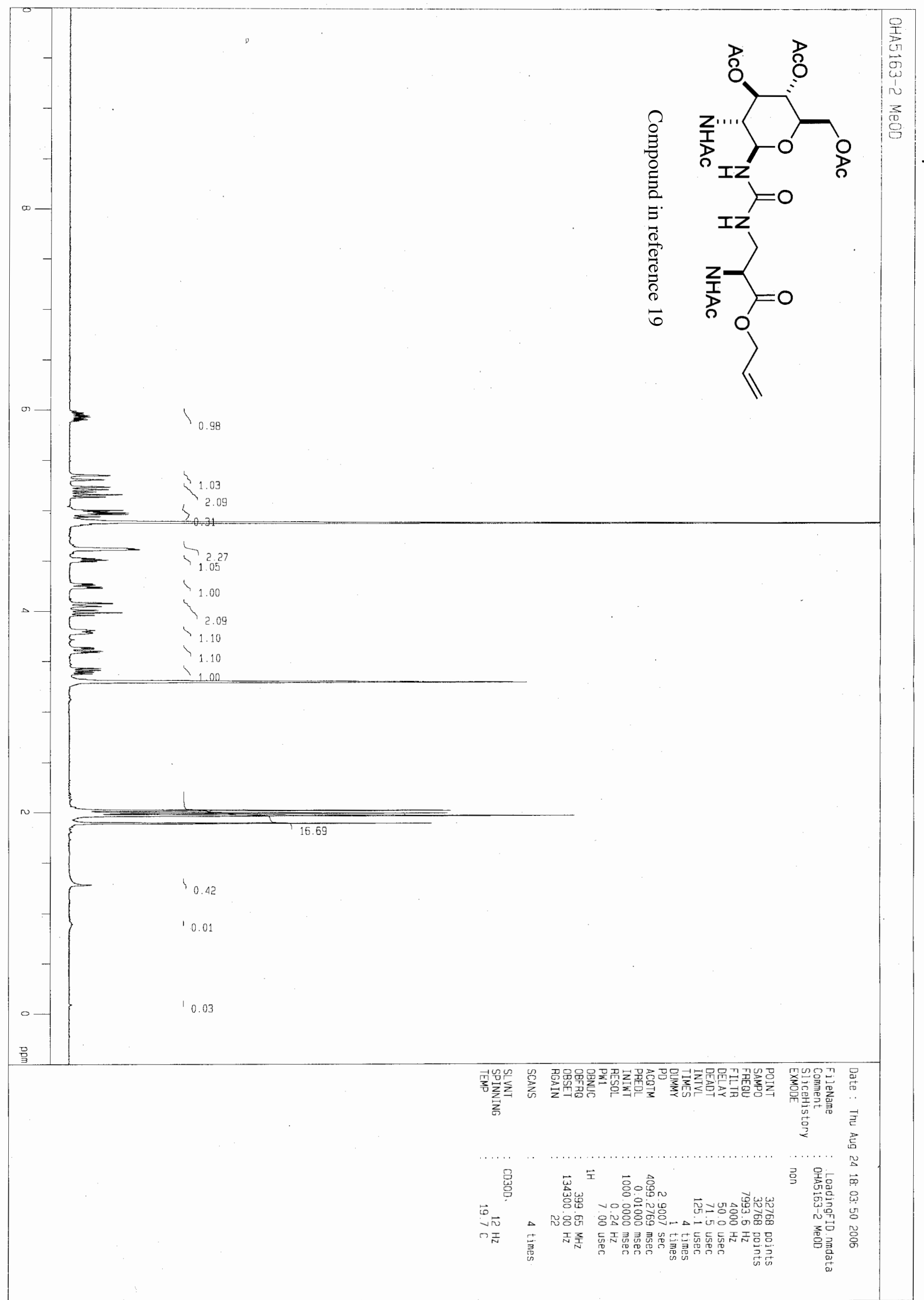



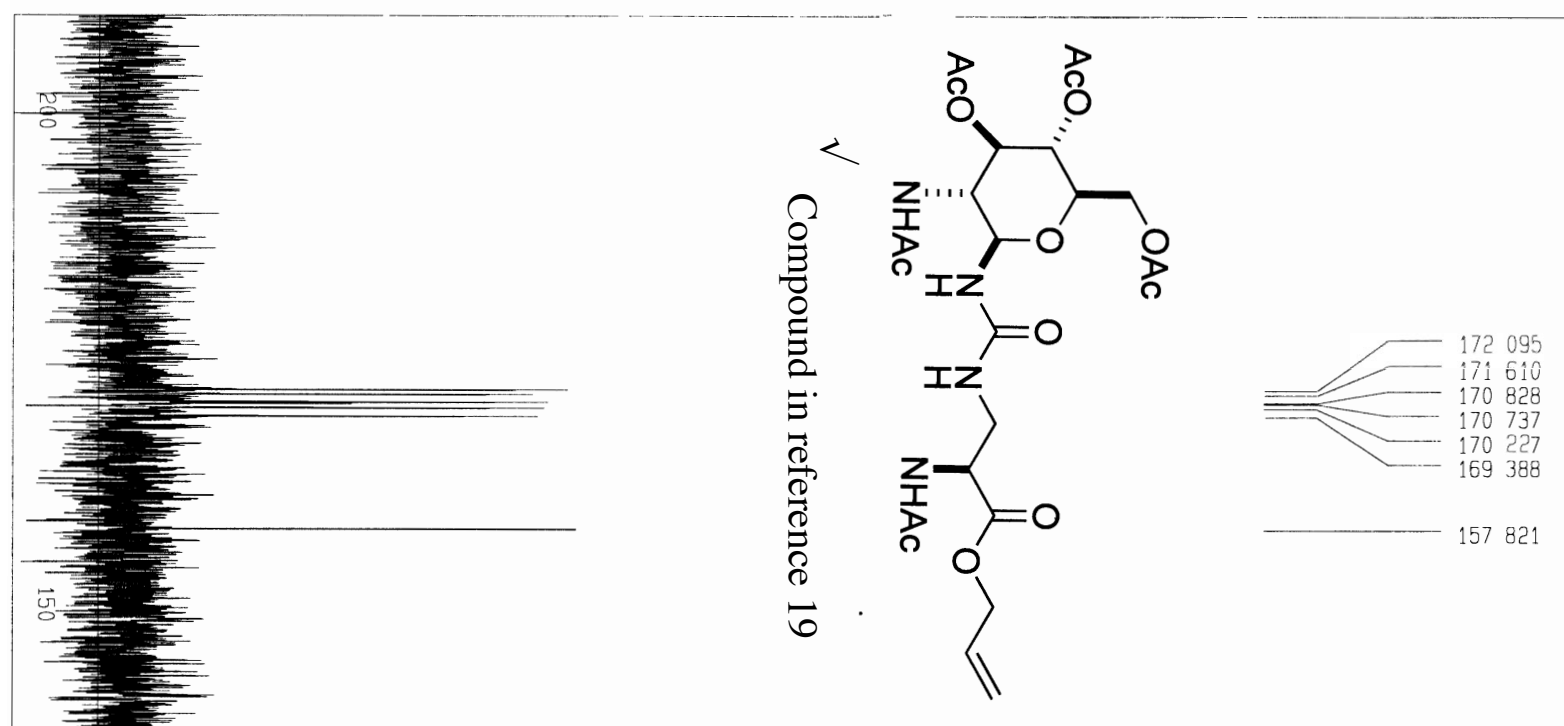

131519

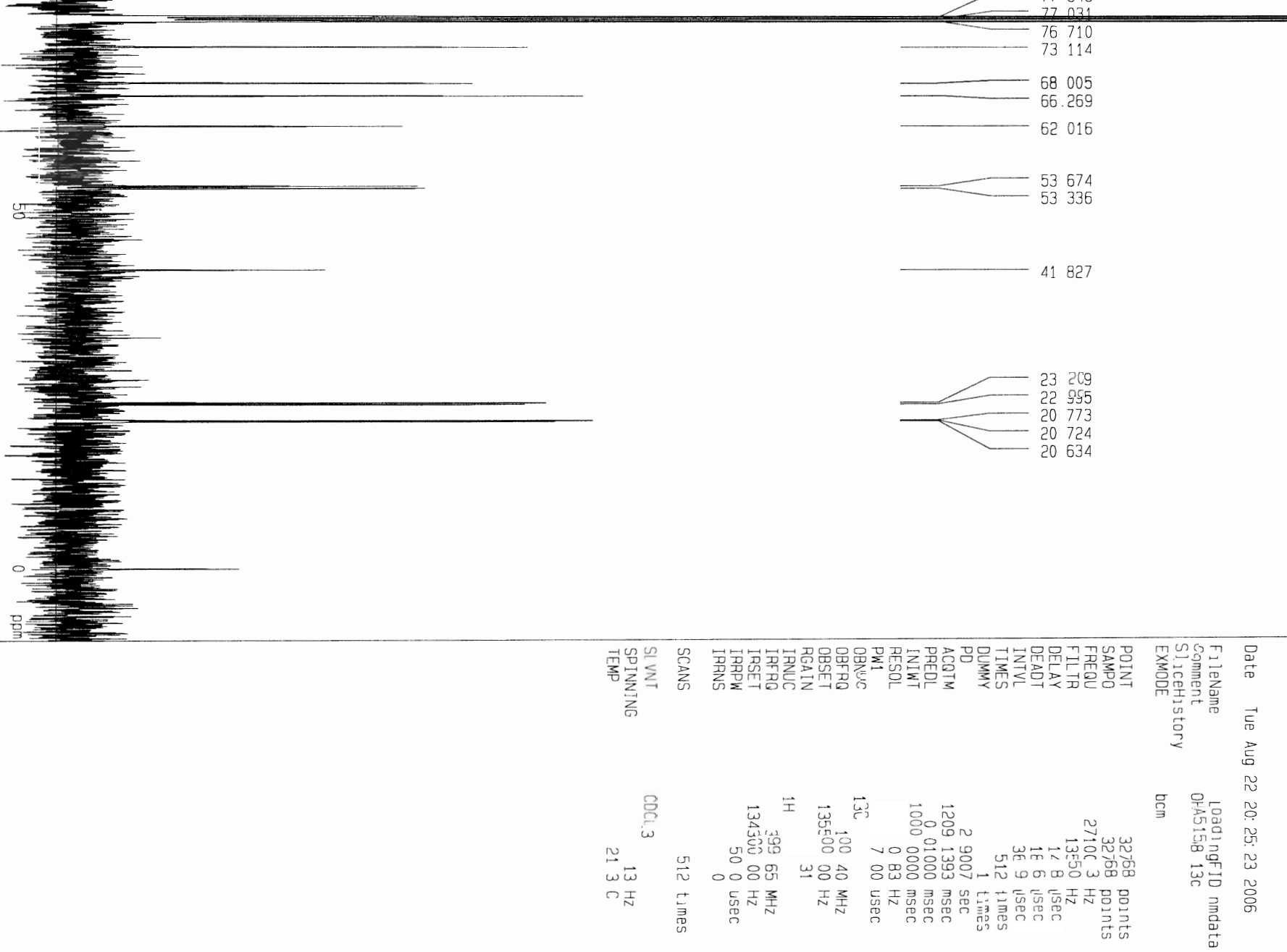




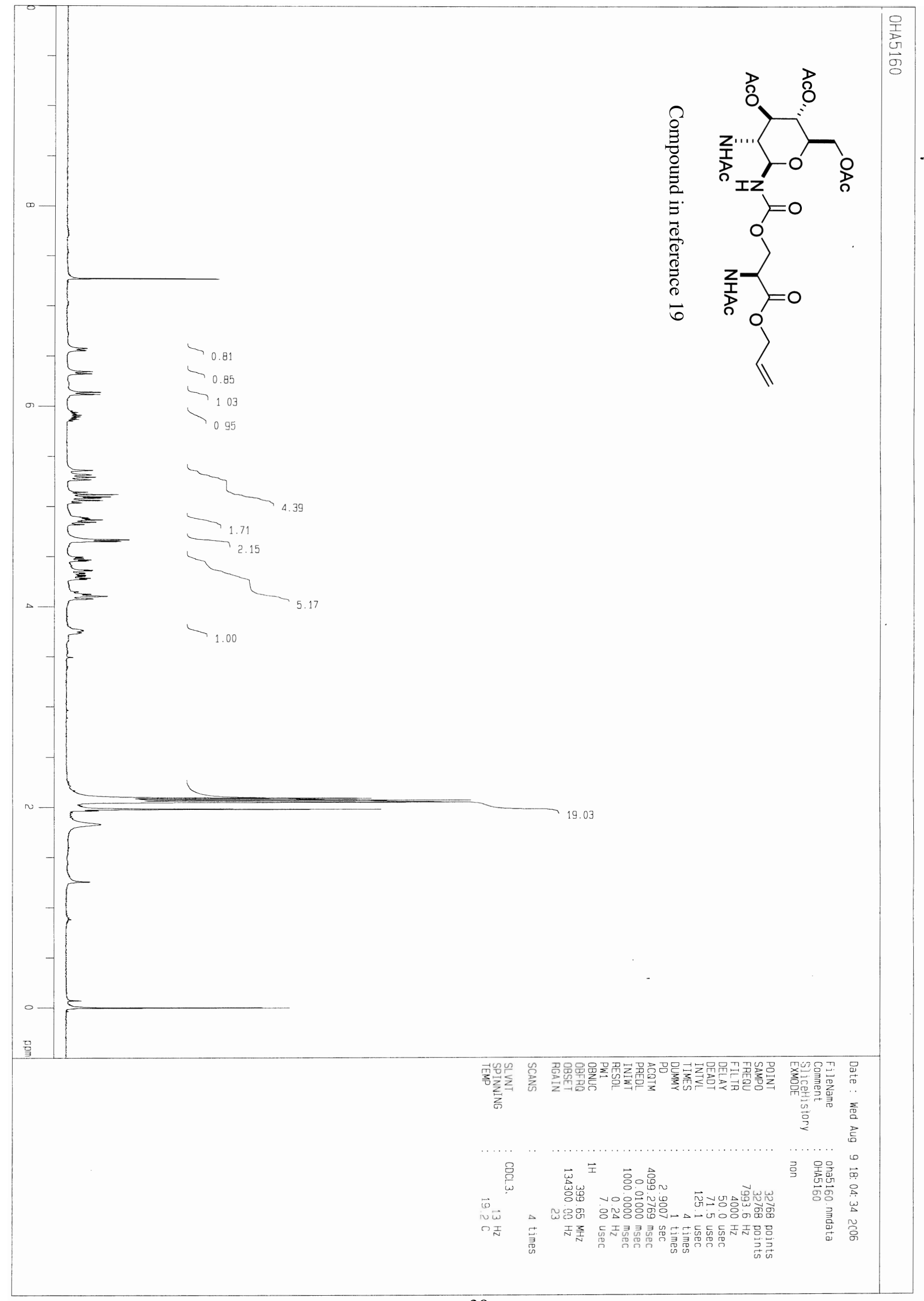




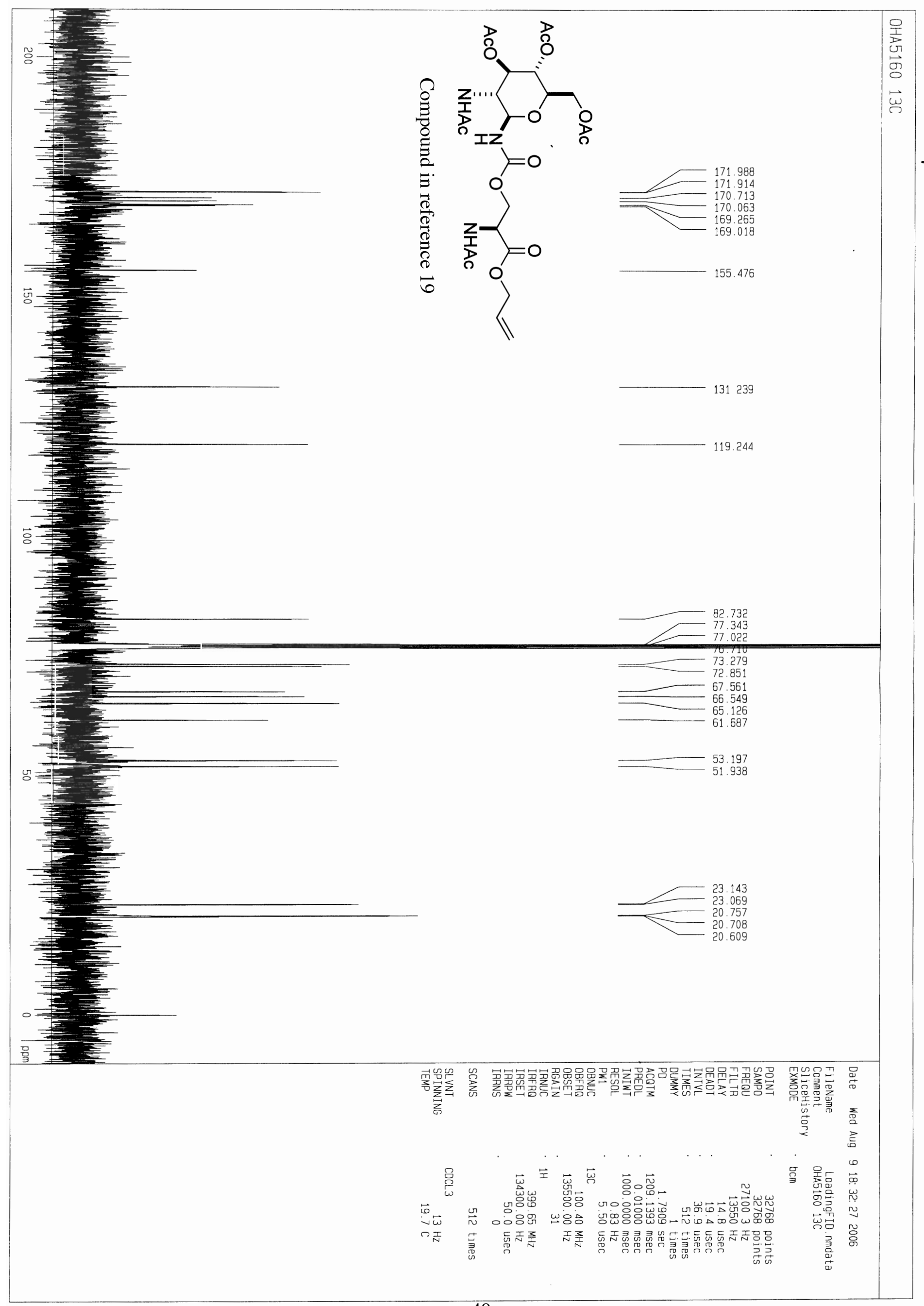

